\title{
ARTICLE OPEN Biofilm formation displays intrinsic offensive and defensive features of Bacillus cereus
}

\author{
Joaquín Caro-Astorga ${ }^{1}$, Elrike Frenzel ${ }^{2}$, James R. Perkins ${ }^{3,4}$, Ana Álvarez-Mena ${ }^{1}$, Antonio de Vicente (iD) ${ }^{1}$ Juan A. G. Ranea ${ }^{4,5}$, \\ Oscar P. Kuipers ${ }^{2}$ and Diego Romero (iD ${ }^{1 *}$
}

Biofilm formation is a strategy of many bacterial species to adapt to a variety of stresses and has become a part of infections, contaminations, or beneficial interactions. In this study, we demonstrate that profound physiological changes permit Bacillus cereus to switch from a floating to a sessile lifestyle, to undergo further maturation of the biofilm and to differentiate into the offensive or defensive features. We report that floating and biofilm cells are populations that differentiate metabolically, with members of each subpopulation developing different branches of certain metabolic pathways. Secondly, biofilm populations rearrange nucleotides, sugars, amino acids, and energy metabolism. Thirdly, this metabolic rearrangement coexists with: the synthesis of the extracellular matrix, sporulation, reinforcement of the cell wall, activation of the ROS detoxification machinery and production of secondary metabolites. This strategy contributes to defend biofilm cells from competitors. However, floating cells maintain a fermentative metabolic status that ensures a higher aggressiveness against hosts, evidenced by the production of toxins. The maintenance of the two distinct subpopulations is an effective strategy to face different environmental conditions found in the life styles of $B$. cereus.

npj Biofilms and Microbiomes (2020)6:3; https://doi.org/10.1038/s41522-019-0112-7

\section{INTRODUCTION}

Bacillus cereus is a widespread bacterium that can colonize a multitude of niches, including soil and seawater, where it survives living as a saprophyte or in transit from other ecological niches. This bacterium can also be found in association with plant tissues, living as a commensal or in symbiosis as a rhizosphere inhabitant. ${ }^{1}$ Mammalian and arthropod guts are also a niche for B. cereus, where it can live as a commensal or a pathogen, either opportunistic or not. ${ }^{2,3}$ The versatility shown by these bacteria evidence the resilience ability against a wide range of environmental conditions. ${ }^{4} B$. cereus gives its name to the $B$. cereus sensu lato group, which includes the phylogenetically similar bacterial species $B$. thuringiensis and $B$. anthracis, diverse in their host impact as they affect insects and human health. ${ }^{5}$ Some strains of $B$. cereus provide benefits to plants, as a promoter of growth (PGP) or biocontrol against microbial diseases, while others are proposed as probiotics for cattle and even for humans. ${ }^{6,7}$ By contrast, there are strains responsible for human pathologies mainly caused by food poisoning, contamination of products in the food industry or even food spoilage. ${ }^{8-10}$ Biofouling, clogging and corrosive consequences of $B$. cereus in industrial devices complete the concerns of humans regarding this bacteria species. $^{10}$

Regardless of the consequences, most of the scenarios listed above are believed to be related with the organization of bacterial cells in biofilms. The formation of biofilms is considered an important step in the life cycle of most bacterial species, and it is known to be related to outbreaks of diseases, resistance to antimicrobials, or contamination of medical and industrial devices. ${ }^{11}$ Approximately $65 \%$ of bacterial human diseases are estimated to involve bacterial biofilms, a number that rise to $80 \%$ for chronic infections. Therefore, these multicellular structures might be considered potential targets to fight against bacterial diseases. $^{12}$ Based on the relevance of bacterial biofilms, our research focuses on elucidating the intrinsic factors employed by $B$. cereus to switch to this sedentary lifestyle. In general, it is known that after encountering an adequate surface, motile bacterial cells switch from a floating or planktonic to a sessile lifestyle followed by the assembly of an extracellular matrix. Studies on biofilm formation in the Gram-positive bacterium Bacillus subtilis have substantially contributed to our understanding of the intricate machinery devoted to efficiently complete this transition. ${ }^{13}$ While studies on biofilm formation on specific $B$. cereus strains indicate that key processes resemble $B$. subtilis biofilm development, clear differences start to be perceived, representative of the evolutionary distance between the two species ${ }^{14}$ : (i) the minor role of the exopolysaccharide of $B$. cereus homologous to the eps $A-O$ of $B$. subtilis in biofilm formation ${ }^{15}$; (ii) the absence of homologues to the accessory protein TapA, necessary for amyloid-like fiber assembly in $B$. subtilis, (iii) the existence of two paralogs of subtilis TasA, i.e., Tas A and CalY ${ }^{16}$; (iv) the absence of the hydrophobic BlsA protein, which coats the biofilm in $B$. subtilis and play a role in the biofilm architecture ${ }^{17} ;(v)$ the differences in the regulatory networks of biofilm formation, lacking the regulatory subnetworks II and III that involve SIrA-SIrR-SinR and Abh; and the gain of the pleiotropic regulator PlcR involved in virulence and biofilm formation; ${ }^{14,18}$ (vii) the absence in $B$. cereus of the lipoprotein Med associated with KinD phosphorylation activity that triggers biofilm formation; and (viii) the different adhesive properties of the spores of $B$. cereus. ${ }^{19}$ Therefore, novel in-depth studies are required not only to confirm similarities between the two microbes but also to highlight unexplored differences.

\footnotetext{
'Instituto de Hortofruticultura Subtropical y Mediterránea "La Mayora" -Departamento de Microbiología, Universidad de Málaga, Bulevar Louis Pasteur 31 (Campus Universitario de Teatinos), 29071 Málaga, Spain. ${ }^{2}$ Department of Molecular Genetics, Groningen Biomolecular Sciences and Biotechnology Institute, Centre for Synthetic Biology, University of Groningen, Nijenborgh 7, 9747 AG Groningen, The Netherlands. ${ }^{3}$ Research Laboratory, IBIMA, Regional University Hospital of Malaga-UMA, 29009 Málaga, Spain. ${ }^{4}$ CIBER de Enfermedades Raras (CIBERER), ISCIII Madrid, Spain. ${ }^{5}$ Department of Molecular Biology and Biochemistry, Universidad de Málaga, Bulevar Louis Pasteur 31 (Campus Universitario de Teatinos), 29071 Málaga, Spain. *email: diego_romero@uma.es
} 
In a previous work, we reported that the growth of $B$. cereus ATCC 14579 (CECT148) biomass of cells adhered to abiotic surfaces is a process that clearly increases with time. ${ }^{16} \mathrm{~A}$ genomic region containing the two paralogous proteins TasA and CalY, the signal peptidase SipW and the locus $B C_{-} 1280$ were proven essential in the transition from planktonic or floating to sedentary and further growth of the biofilm. The differences found in $B$. subtilis in this and other reports led us to investigate which are the additional intrinsic genetic features that warrant $B$. cereus to solve hypothetical environmental situations by the assembly of biofilms. The combination of two techniques, RNA sequencing (RNA-seq) and mass spectrometry proteomic (isobaric tags for relative and absolute quantitation-iTRAQ), enabled us to acquire solid evidence of the global changes differentiating floating from biofilm programmed cells and depict how biofilm of $B$. cereus progresses. We report the reinforcement of the cell wall of biofilm cells, that would prepare cells for further assembly of macromolecules as polysaccharides and other adhesins, and additional protection of cells individually from external aggressions; and the major production of secondary metabolites of biofilm-associated cells to defend against competitors. Additionally, floating cells are maintained in a sustained stationary phase of growth conducive to survival, not in the form of spores, and more aggressive against the human host. Our findings argue in favor of the metabolic versatility of $B$. cereus, that can be programmed, in response of the new microenvironment conditions or a combination of both. Furthermore, we describe a fine tuning in gene expression, which permit this specie to maintain the two distinct subpopulations necessary to face changeable environmental conditions.

\section{RESULTS AND DISCUSSION}

Massive changes in gene expression define the physiological state of biofilm and floating cells

To study the transition of cells from floating to biofilm and its further progression, we used static cultures and developed the experimental setup summarized in Supplementary Fig. 1 (described in detail in the section Methods). Regarding biofilm formation as a developmental program, we considered $24 \mathrm{~h}$ cultures as the initial time to perform the comparison, when biomass started to be visible and thus suitable for collection and further analysis. This comparison allowed us to define the initial changes in gene expression. which characterize sessile or floating cells in young biofilms. This comparison was used as a reference and a further time-course analysis was made to study the changes arising at $48 \mathrm{~h}$, when the biofilm is consolidated in thickness and adherence, and at $72 \mathrm{~h}$, when the biofilm is fully mature (Supplementary Fig. 2a). ${ }^{16}$

Although transcription and translation are intimately associated in bacteria in space and time, there are other factors that can alter the final amount of protein and, subsequently, the final function trusted in those proteins. In $B$. cereus, it has been reported that mRNA shows a half-life ranging from $1-15 \mathrm{~min}^{20}$ Several studies on Bacillus species classify the total amount of proteins inside a cell into two protein populations of either a labile fraction or a fraction of long-lived proteins with a turnover ranging from less than 1-40 h, which can introduce large differences between mRNA transcripts and protein function. ${ }^{21}$ Therefore, our samples were analyzed by two complementary quantitative techniques directed to two steps in gene expression: (i) sequencing total mRNA analysis and (ii) quantitative proteome analysis using isobaric tags for relative and absolute quantitation (iTRAQ). Like RNA-seq, iTRAQ is very accurate in defining quantitative differences, although it requires a relatively large amount of protein. Thus, RNA-seq data were considered as a reference in our study for gene expression, and the iTRAQ data were used to confirm that variations in gene expression result in the same direction as variations of translation. Henceforth, confirmed bacterial factors will be indicated with an asterisk "**" and discordances with a " $x$ ". The absence of a mark means that this protein was not detected by ITRAQ.

The genome of B. cereus ATCC 14579 possesses 5490 open reading frames (ORFs), and the RNA-seq analysis showed that 1292 genes were differentially expressed $(\log 2<>|2|)$ in biofilmassociated cells compared to floating cells, meaning $23.5 \%$ of the total gene content. These numbers are illustrative of the outstanding genetic machinery dedicated to the developmental program that leads to the formation of a bacterial biofilm (Supplementary Fig. S2b, c). Proteomic analysis revealed 945 proteins with differential expression $(\log 2>|0.7|)$ at any of the times sampled. A wider view of the data indicates a good correlation between both techniques in the number of genes with up or down expression levels (Fig. 1a). Although the initial putative suspicion on the relative low concordance of transcription and translation, discordances among mRNA and protein levels were limited to only 43,9 , and 21 hits at 24,48 , and 72 h, respectively, a finding that shows a first confirmation of data.

To obtain a detailed view of the major physiological changes, genes with differential expression were sorted into Cluster of Orthologous Groups (COG) categories (Fig. 1b, Supplementary Fig. 3). The data showed some foreseen changes such as the downregulation of the COG for flagellum assembly compared to that of floating cells. Delving into more detail, as COG categories ignore many of the individual differentially expressed ORFs, manual classification of the 1292 genes into functional groups was performed. This manual classification also showed an expected behavior in $B$. cereus in terms of sporulation, which group of genes are upregulated as it is linked to biofilm formation. In addition, some known regulators of sporulation, such as the positive biofilm regulator $\mathrm{Sinl}_{1}{ }^{22}$ are upregulated, while the negative biofilm regulator $\mathrm{PlcR}$, which is negatively controlled by $S p o 0 A-P^{23}$ is downregulated.

We wondered if there were time-specific functional changes along biofilm development or if biofilm physiological state is triggered just by upregulating and downregulating a number of genes. Most of the functions show a more pronounced up or downregulation over time. Although, at $24 \mathrm{~h}$, genes of pyrimidine metabolism were specifically upregulated in biofilm cells (Table 1) and sporulation genes were abruptly downregulated at $72 \mathrm{~h}$. Clustering of the 124 sporulation-related genes by expression pattern using the Short Time-series Expression Miner (STEM) showed an increase of expression at $24 \mathrm{~h}$ and $48 \mathrm{~h}$ and repression at $72 \mathrm{~h}$ of biofilm formation (Supplementary Fig. 4a). Cluster 6 of the STEM clustering results (Supplementary Fig. 4b) showed a small group of genes with an overexpression pattern at $72 \mathrm{~h}$ compared to previous stages, but these genes are specific negative sporulation regulators. Despite the arrest in the expression of sporulation genes, the sporulation process inertia reveals a $9 \%$ of spores within the $72 \mathrm{~h}$ biofilm (Supplementary Fig. 10).

These time-resolved analyses indicate that most of the biofilm functions are intrinsically associated with the biofilm state, with the only exceptions of pyrimidines metabolism and sporulation, only required in specific developmental stages.

Changes in the metabolic activity of biofilm cells to satisfy the synthesis of the new extracellular matrix

It appears that cells committed to the biofilm lifestyle have specialized in certain metabolic pathways most likely directed to the synthesis of proteins, polysaccharides and extracellular DNA (eDNA), elements of the extracellular matrix necessary to cover a range of functions from adhesion to biofilm architecture. ${ }^{17,24,25}$ The extracellular matrix plays an important role in defense against physical stress like desiccation. ${ }^{26}$ In our results, we found 
A)

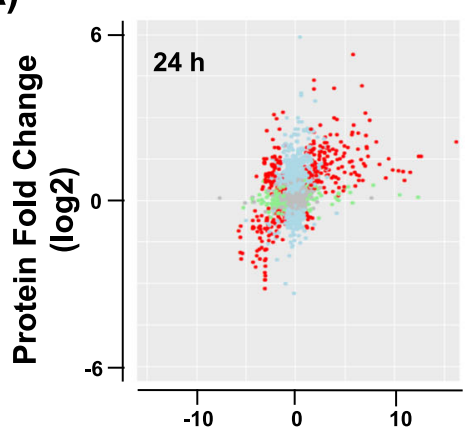

Fold Change: RNA vs Proteins

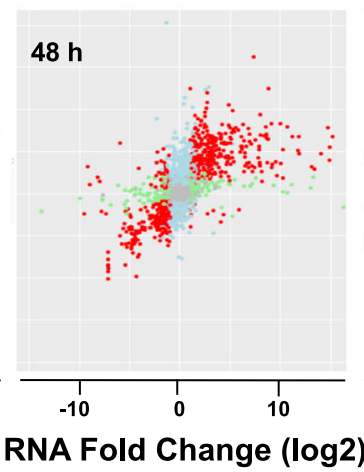

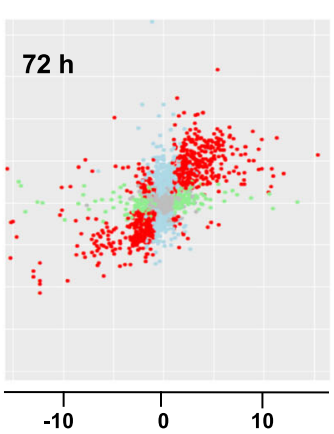

Significant

- Both

Neither

Protein only

RNA only
B)

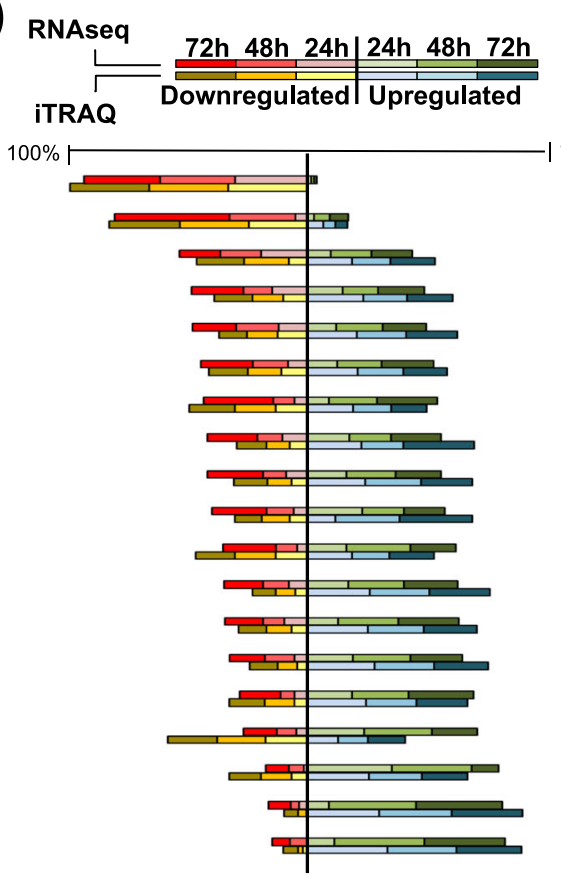

\section{Relative distribution} (Number of genes)

$100 \%$

Cell motility

Translation, ribosomal structure and biogenesis

Replication, recombination and repair

Posttranslational modification, protein turnover

Signal transduction mechanisms

Energy production and conversion

Transcription

Defense mechanisms

Function unknown

Cell cycle control, cell division

Carbohydrate transport and metabolism

General function prediction only

Amino acid transport and metabolism

Inorganic ion transport and metabolism

Coenzyme transport and metabolism

Cell Wall/membrane/envelope

Nucleotide transport and metabolism

Lipid transport and metabolism

Secondary metabolites biosynthesis, transport and catabolism

Fig. 1 Validation of variation of gene expression using RNA-seq and iTRAQ analyses. a Fold-change in expression between transcriptomic (RNA-Seq) and proteomic (iTRAQ) results from samples at 24, 48, and $72 \mathrm{~h}$. Points show significant changes (adjusted $p$-value $<0.05$ ) according to both technologies (red), changes only found in proteomic (blue) or only found in transcriptomic (green). Gray dots represent items detected with statistically no significant changes. The top right and bottom left quadrants show concordant directions of change between both technologies; the top left and bottom right show conflicting directions. b Relative comparison of COG categories of genes and proteins. Total number of elements of each category were relativized to a percentage and distributed in down or upregulated. This graph shows that the ratio of elements that are up or downregulated within each COG category is conserved, revealing similar results in terms of functional categories among RNA-seq and iTRAQ techniques.

overexpression of multiple genes involved in the synthesis of the extracellular matrix (Fig. 2a). Our analysis revealed that the wellknown structural biofilm-related genes $\operatorname{sip} W$-tas $A$ operon and calY $\left(B C 1278^{*}, B C 1279^{*}, B C 1281^{*}\right)$ are overexpressed in biofilmassociated cells. Not surprisingly, and in agreement with findings from $B$. subtilis biofilm studies, the master regulator that controls the expression of these genes, SinR, and its repressor Sinl, ${ }^{27}$ were upregulated in biofilm-associated cells. In a previous work, the genes purA (BC5468), purC (BC0326), and purL (BC0327), which are implicated in purine biosynthesis, were demonstrated to be indispensable for biofilm formation in B. cereus. ${ }^{28-30}$ In our analysis biofilm cells upregulate the entire gene cassettes for pyrimidine $(B C 3883-89)$ and purine $\left(B C 0325-B C 0332^{*}\right)$ biosynthesis, as well as transporters of amino acid and formate synthesis required for nucleoside synthesis (BC0403*, BC0639, BC0640*, BC2383, $\left.B C 3939^{*}, B C 2790\right)$, nucleoside transporters (BC2973, BC0363) and specific phosphate transporters (BC4265-68 and BC0711), all molecules required for DNA synthesis. These results suggest that these metabolic changes might be, among others, oriented to the synthesis of the eDNA of the extracellular matrix.

In addition to proteins and eDNA, exopolysaccharides (EPSS) constitute an integral component of the extracellular matrix of most bacterial biofilms. Importantly, our data indicate noticeable differences in the well-defined role of EPS in B. subtilis. First, the putative EPS gene cluster $B C 5263-B C 5279^{*}$ (Fig. 2b, top) homologous to the eps operon of $B$. subtilis, showed a similar expression pattern to that of floating cells. Indeed, knockout mutants in this genetic region (herein eps 1 ) were not arrested in biofilm formation based on the crystal violet staining of the adhered biomass (Fig. $2 \mathrm{~b}$, bottom). This finding is in agreement with previous studies showing that mutants in this gene cluster in B. cereus 905 did not affect biofilm formation. ${ }^{19}$ Second, we identified an additional gene cluster (herein eps2), annotated as a capsular polysaccharide synthesis, which is overexpressed in biofilm-associated cells 
J. Caro-Astorga et al.

Table 1. Genes of the pyrimidine metabolism specifically upregulated in biofilm cells.

\begin{tabular}{|c|c|c|c|c|c|}
\hline Gene ID & \multicolumn{5}{|c|}{ Log2 (fold-change) } \\
\hline BC0326 & 3.13 & 3.87 & -0.69 & Purine biosynthesis pathway. Phosphoribosylaminoimidazole-succinocarboxamide synthase & * \\
\hline ВC0327 & 3.09 & 3.37 & -0.66 & Purine biosynthesis pathway. Phosphoribosylformylglycinamidine synthase subunit PurS & * \\
\hline BC0328 & 2.91 & 3.37 & -0.80 & Purine biosynthesis pathway. Phosphoribosylformylglycinamidine synthase I & * \\
\hline BC0331 & 2.96 & 3.52 & -1.96 & Purine biosynthesis pathway. Phosphoribosylaminoimidazole synthetase & * \\
\hline BC0332 & 4.01 & 3.68 & -1.38 & Purine biosynthesis pathway. Phosphoribosylglycinamide formyltransferase & * \\
\hline BC3882 & 3.66 & -0.38 & -0.07 & Pyrimidine biosynthesis pathway. Orotate phosphoribosyltransferase & * \\
\hline BC3883 & 3.73 & 0.65 & 0.84 & Pyrimidine biosynthesis pathway. Orotidine 5'-phosphate decarboxylase & \\
\hline BC3884 & 4.14 & 1.06 & 1.54 & Pyrimidine biosynthesis pathway. Dihydroorotate dehydrogenase $1 \mathrm{~B}$ & \\
\hline BC3888 & 5.69 & 2.74 & 2.27 & Pyrimidine biosynthesis pathway. Dihydroorotase & \\
\hline BC3889 & 4.87 & 1.78 & 0.26 & Pyrimidine biosynthesis pathway. Aspartate carbamoyltransferase & \\
\hline
\end{tabular}

(BC1583-BC1591) (Fig. 2b, top). In agreement with a previous report, we could not microscopically visualize a capsule in this strain of $B$. cereus, which led us to propose a role of this new gene cluster (BC1583-BC1591) in biofilm formation. A mutant in this region was not completely arrested but was partially impaired in the biofilm adhered to the wells (Fig. $2 b$, bottom). This deviation of phenotype was reversed by expressing the entire eps 2 region in trans, in a replicative plasmid under control of an IPTG inducible promoter (eps2, PIPTG-eps2). Attending to these results, we hypothesize that eps 2 region play a role in biofilm formation.

The biofilm architecture is very resource-consuming. The supply of amino acids might come from protein recycling or being compensated by downregulation of the synthesis of other polymers such as flagellum assembly, but this supply seems to be insufficient, according to our results. ${ }^{31}$ We found a noticeable upregulation of genes encoding transporters of specific amino acids (Supplementary Table 1), especially those genes encoding a glutamine transporter and a glutamine-binding protein, which were significantly upregulated in comparison to other specific amino acid transporters. Glutamine is an important amino acid in bacterial physiology, and beyond the well-known involvement in the synthesis of proteins, this amino acid serves additional functions as a growth control molecule through dynamic gradients of glutamine concentration along the colony. This gradient induces and reduces the metabolic activity of cells to allow nutrients to diffuse to the inner part of the biofilm. ${ }^{32,33}$ Apart from this, the glutamine supply is consumed for important functions, such as the synthesis of the protein component of the extracellular matrix or cell wall poly-linking. The synthesis of amino acids is under the control of DnaK (BC4858), a suppressor protein homologous to DksA in $E$. coli, which is a negative regulator of rRNA general expression during starvation and a positive regulator of several amino acid biosynthesis, amplifying the effects of the secondary messenger ppGpp. In E.coli, DksA is present at similar concentrations at mid-log phase and in late stationary phase with unchangeable levels; however, the levels during biofilm formation were not explored. ${ }^{34}$ In a biofilm of $B$. cereus, levels of DnaK are remarkably upregulated compared with that of floating cells. This led us to speculate that DnaK belongs to the complex biofilm regulatory network that participates in the coordination and synchronization of the protein synthesis machinery required for biofilm formation in $B$. cereus.

Biofilm-associated cells thicken their cell wall

In addition to the collective protection to antimicrobials that can be provided by the extracellular matrix, our data suggest that individual cells might develop protection against external aggressors by enhancing the physical barrier represented by the cell wall. Moreover, in B. subtilis, it has been reported the importance of transglycosylation and transpeptidation of the PG, as well as the wall teichoic acid for biofilm formation, which disturbance affect the cell wall structure and drastically affect the extracellular matrix anchoring. ${ }^{35,36}$ Lipoteichoic acid (LTA) is a major component of the cell wall in Gram-positive bacteria, and the LTA synthase (BC3765) is upregulated in $48 \mathrm{~h}$ and $72 \mathrm{~h}$ aged biofilms. Peptidoglycan (PG), the other main component of the cell wall, is composed of units of $\mathrm{N}$-acetylglucosaminic acid and $\mathrm{N}$ acetylmuramic acid. In our experiments, we found that cell wall degradation enzymes are downregulated (BC0888*, BC5237, $B C 3257, B C 1660, B C 3677)$, except for the N-acetylmuramoyl-Lalanine amidase $\left(B C 2823^{*}\right)$, which is specifically upregulated in biofilm cells. In addition, several penicillin-binding proteins $(B C 1469, B C 2190 * B C 2448, B C 2688, B C 4075)$, which are involved in the final stages of PG synthesis, are upregulated in biofilms with a maximum expression level at $48 \mathrm{~h}$, as well as three transpeptidases (BC2468*, BC5027, BC0771), which catalyze the PG crosslinking (Fig. 3a). D-alanine is an important component of the cell wall which is implicated not only in the peptide cross-linking but also in the D-alanylation of teichoic acid, a modification reported to contribute to the resistance to several antimicrobials in $B$. cereus, $^{37}$ and to biofilm formation, host defense or mouse intestinal tract colonization in other Gram-positive bacteria. ${ }^{38-41}$ The bidirectional conversion of L-alanine into $D$-alanine is catalyzed by alanine racemases, and BC0264 is upregulated at $24 \mathrm{~h}$ and $48 \mathrm{~h}$. These gene are orthologous to Dal-1 in B. anthracis, which is known to rescue the phenotype of a D-ala auxotrophic strain of E. coli. ${ }^{42}$ These findings on the upregulation of the enzymatic machinery involved in PG, LTA, and D-alanine synthesis in conjunction with the downregulation of enzymes implicated in 
A)

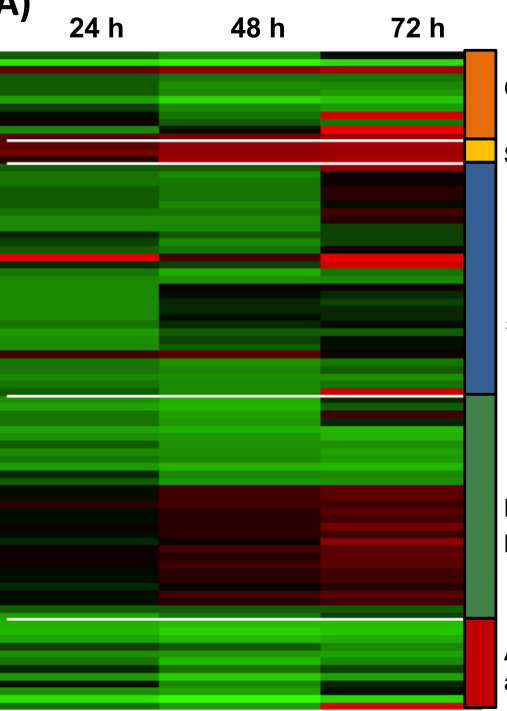

Cell Wall
S-layer
Nucleoside
synthesis
Exo-
polysaccharides
Adhesins and
amyloid fibres

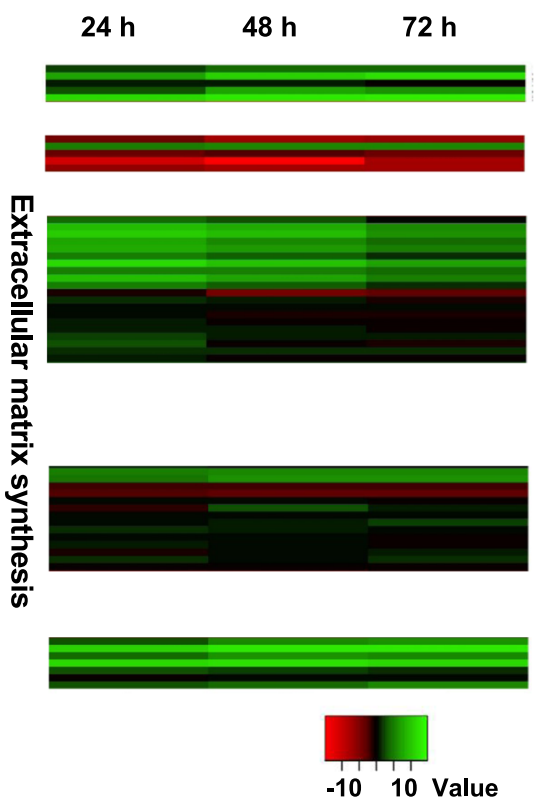

B)

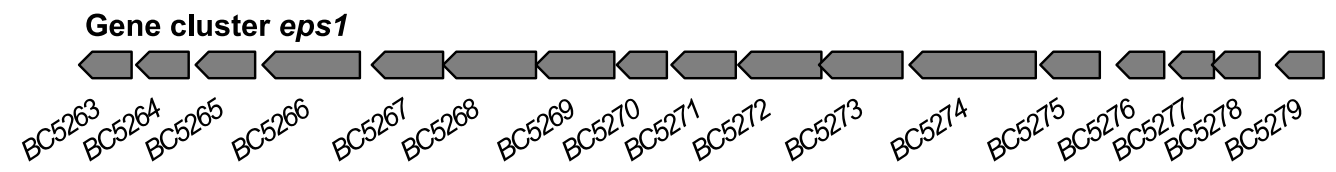

\section{Gene cluster eps2}

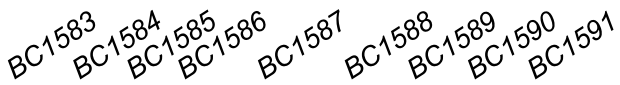

WT

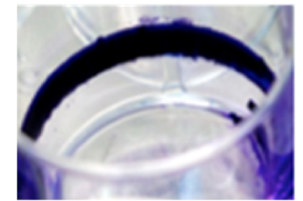

eps2

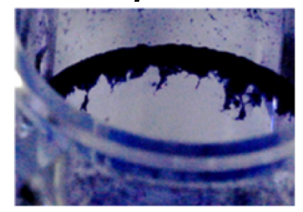

\section{eps1}

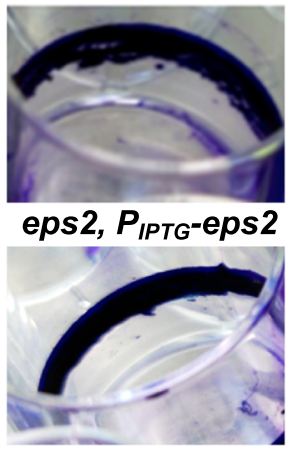

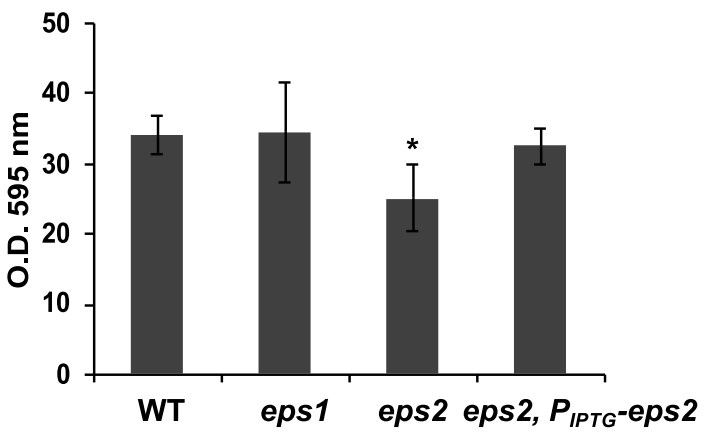

Fig. 2 Expression dynamics of external elements and extracellular-matrix components during biofilm formation. a Expression dynamics of external elements and extracellular-matrix components during biofilm formation. Comparison of heat maps from RNA-seq (left) and iTRAQ (right) results at 24,48 , and $72 \mathrm{~h}$, over a selection of elements of the outer layers of $B$. cereus cells and components of the extracellular matrix shows the following: (i) The low expression levels of S-layer components, the major relevance of eDNA at 24-48 h, and the continuous overexpression of factors related to cell wall synthesis, some exopolysaccharides and other adhesins. $\mathbf{b}$ Gene clusters for the synthesis of two hypothetical exopolysaccharides: top, eps 1 , homologous to the eps region in $B$. subtilis and bottom, eps 2 specific of $B$. cereus. Crystal violet staining of adhered biofilms showed no differences between eps1 single mutant and wild-type, and slight reduction of biofilm formation of eps2 single mutant. The strain eps2 complemented with a replicative plasmid (pUTE973) harboring the transcriptional construction $\mathrm{P}_{\mathrm{IPTG}}{ }^{-}$ eps 2 showed a reversion on the crystal violet staining. Pictures were taken $72 \mathrm{~h}$ after growing cells with no agitation at $28^{\circ} \mathrm{C}$ in TY. The adhesion to abiotic surface of the different strains in TyJ medium at $48 \mathrm{~h}$ was measured by the amount of crystal violet retained in the bacterial biomass. (error bars correspond to SD.*, differences statistically significant, $p<0.05$, T-student, three replicates).

cell wall degradation in biofilm cells, raised the question of whether there is an alteration in the cell wall thickness of biofilmassociated cells compared to floating cells. To explore this hypothesis, we measured the cell wall thickness of cell sections of $48 \mathrm{~h}$ biofilm and floating cells by electron microscopy, revealing a $33.4 \%$ increase in the cell wall thickness of biofilm cells, a structural change which was also observed in sporulating cells (Fig. 3c). 


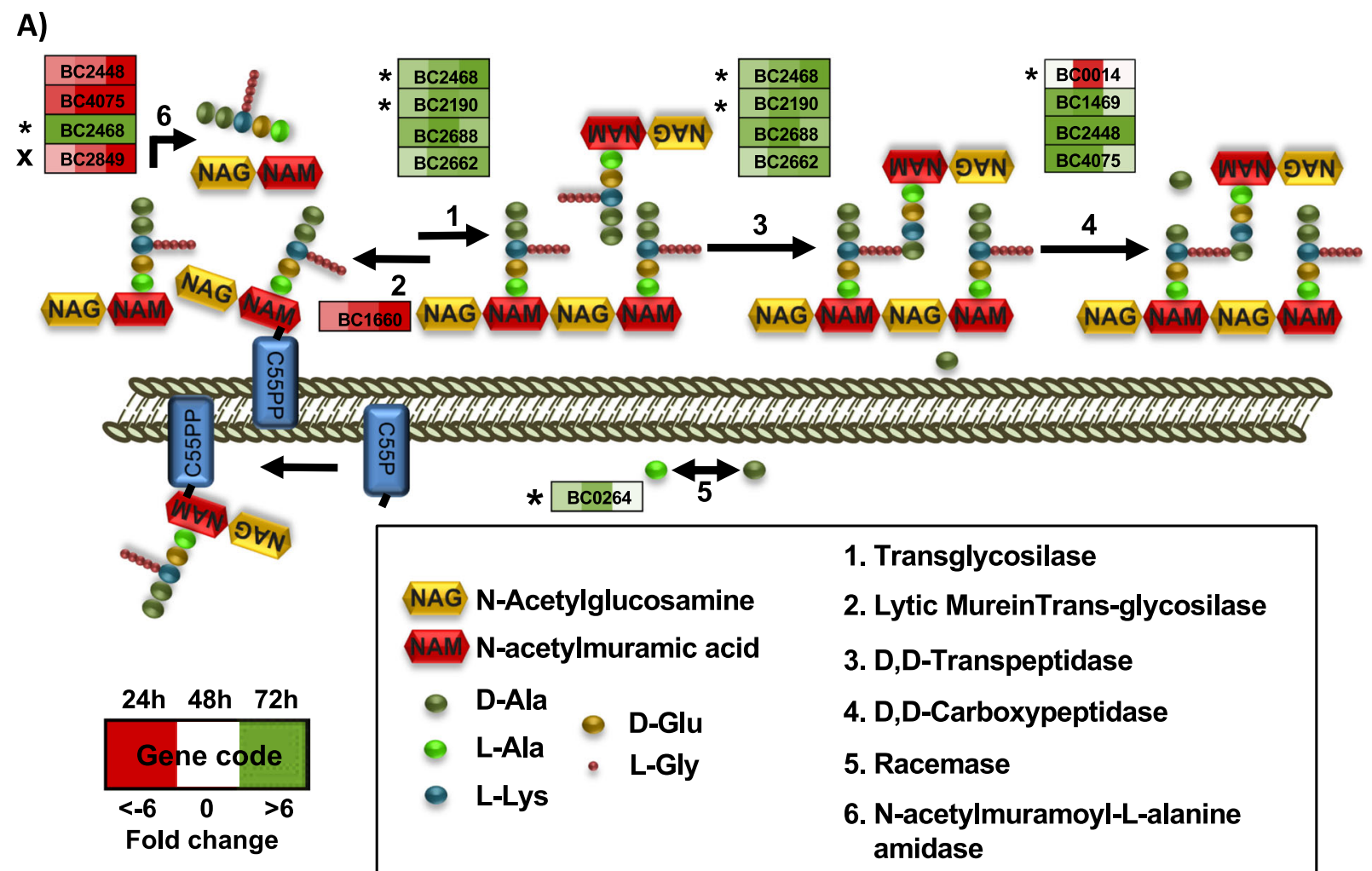

B)
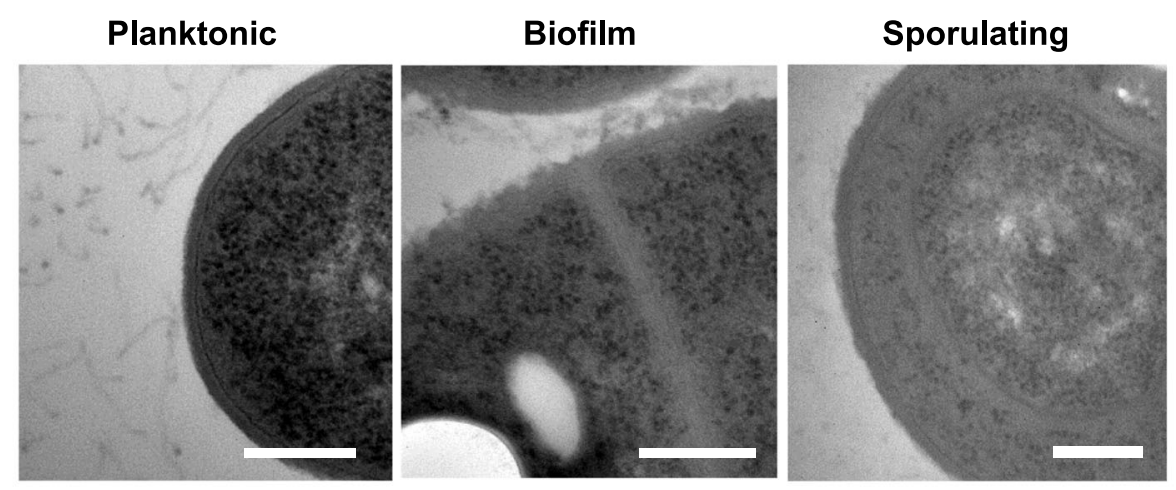

Cell Wall thickness $(\mathrm{nm})$

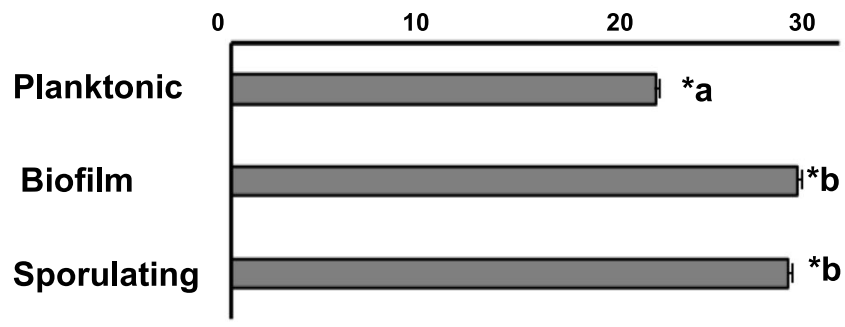

Fig. 3 Cells in a biofilm increase the thickness of the cell wall. a Scheme of the extra cytoplasmic cell wall synthesis pathway. Each step is performed by several genes represented in boxes. Colored squares inside boxes represent 24,48 , and $72 \mathrm{~h}$ sampling times, and the intensity of color shows the level of upregulation (green) or downregulation (red). Stars indicate confirmation of the behavior by iTRAQ results and cross indicate conflicting results. $\mathbf{b}$ Transmission electron micrographs of floating cells, biofilm cells and sporulating cells inside the biofilm structure. Measurements of the cell wall thickness was done with ImageJ Fiji software over 40 images and 300 measures around the edges of each cell, showing an increase of $33.4 \%$ in the thickness of biofilm and sporulating cells. Standard deviation SC $<0.01$. Bars equal $200 \mathrm{~nm}$.

Biofilm-associated cells produce higher amount of secondary metabolites

Physical stresses are mainly buffered by the extracellular matrix, but how can bacteria defend from attacks from other bacteria in the competition for the space in the soil, plant rhizosphere or human gut? One way in which sessile bacterial cells may efficiently fight competitors regards the offense inflicted by antimicrobials. B. cereus possesses several genomic regions 
dedicated to the production of secondary metabolites with antimicrobial activity. In addition to these, we found genes with unknown functions that after in silico analysis (see the section Methods) appeared to be hypothetically involved in the production of putative secondary metabolites. Interestingly, all of them are upregulated in biofilm-associated cells (Supplementary Table 2). Among those regions were genes encoding NRPS/PKS or putative bacteriocin-synthesizing proteins such as (i) thiocillin, (ii) tylosin-like, (iii) bacitracin, (iv) porphyrins, (v) a putative member of the heterocycloanthracin/sonorensin family of bacteriocins; (vi) other putative bacteriocin $(B C 1248-50)$ vii) the cluster $B C 1210$ $B C 1212$ orthologous to a streptomycin synthesis gene cluster in $B$. subtilis; and (viii) a colicin-like toxin. Colicin is a bacteriocin, which has been proposed to play an important role in microbial competition in the gut and to facilitate intestinal colonization. ${ }^{43}$ There is a gap in the study of secondary metabolites in B. cereus to confirm that these genomic regions are responsible for the synthesis of active compounds. Only thiocillin has been studied in detail and has been proven to produce an active peptide. As the ITRAQ method is unable to detect these peptides and given that this antimicrobial is presumably produced in higher amounts by biofilm cells, we analyzed the presence of this metabolite in floating and biofilm cells fractions using mass spectrometry. This analysis confirmed that thiocillin was present in the pellet and supernatant of biofilm cells, but below detectable levels in the pellets of floating cells and in the spent medium (Fig. 4 and Supplementary Fig. 5). Based on this observation, one might speculate that the production of these antimicrobials is used to colonize a niche and for protection against competitors, which are in close contact in the direct surroundings.

Reactive oxygen species (ROS) are well-known factors that elicit the so-called 'antimicrobial-mediated killing' and are discussed to be the final cause of bacterial cell death instead of the direct effect of antimicrobials. ${ }^{44}$ ROS production has also been described to be part of the defensive response of plants and mammals to fight against pathogen invasions. ${ }^{45}$ Bacteria produce several enzymes, which neutralize ROS, either preventing or reducing cell damage as well as other repairing enzymes. According to the protective mode, which characterizes the lifestyle of biofilm cells, our analyses revealed the overexpression of enzymes devoted to scavenging diverse ROS: catalase (BC3008), superoxide dismutases $(B C 1468, B C 4907)$, chloroperoxidase (BC4774), alkylhydroperoxidase $(B C 2830$,$) , and glyoxalases \left(B C 5092^{*}, B C 3178, B C 0824\right)$. Additionally, iTRAQ analysis showed higher amounts of glutathione peroxidase (BC2114), glyoxalases (BC5092, BC3532), superoxide dismutase $(B C 4272)$, thioredoxin-dependent thiol peroxidase (BC0517), thiol peroxidase (BC4639), and hemedependent peroxidase (BC5388) in biofilm-associated cells (Fig. 5a). We wondered what could be the reason of the overexpression of the ROS detoxification machinery. In this direction we additionally observed metabolic changes to prevent the production of ROS: (i) downregulation of the tricarboxylic acid (TCA) cycle $\left(B C 1251^{*}, B C 3833^{*}, B C 3834^{*}, B C 1790^{*}, B C 0466^{*}\right.$, $\left.B C 1712^{*}, B C 0466^{*}\right)$, including Complex II of the electron transport chain (BC4516*, BC4517*), which supplies two electrons to ubiquinone (Fig. 5b and Supplementary Fig. 6); (ii) overexpression of Complex I of the electron transport chain, increasing the total amount of the flavin mononucleotide (FMN) which receives the electron from $\mathrm{NADH}^{46}$; and (iii) activation of the glyoxylate shunt (isocitrate lyase $B C 1128^{*}$, malate synthase $B C 1127^{*}$ ), a bypass of the TCA which converts isocitrate to glyoxylate to malate. This shunt yields less reducing power, and indirectly increases the concentration of $\mathrm{NAD}^{+}$, which have been proven to arrest superoxide production by Complex I, and complementary being implicated in the level of tolerance to antibiotics. ${ }^{47}$

A)

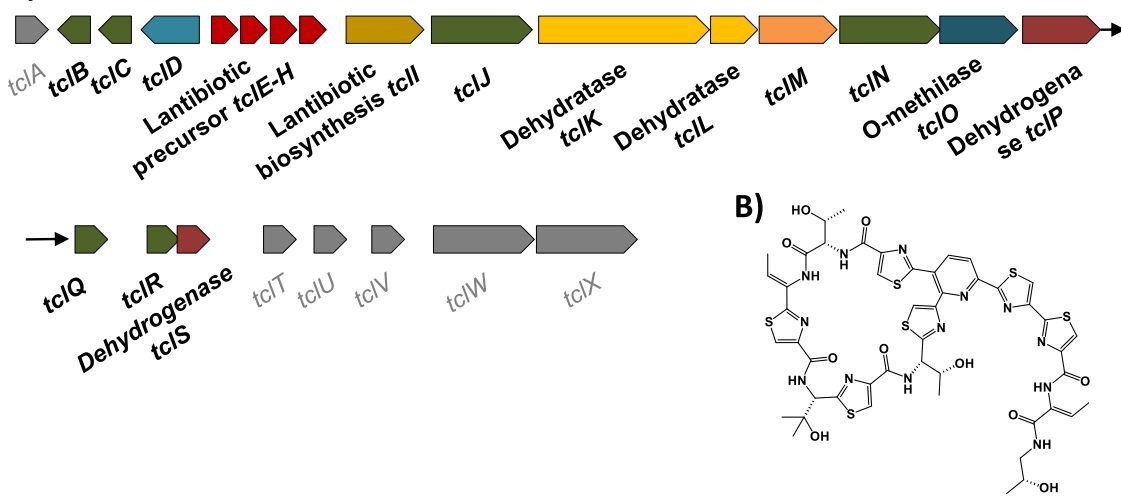

C)

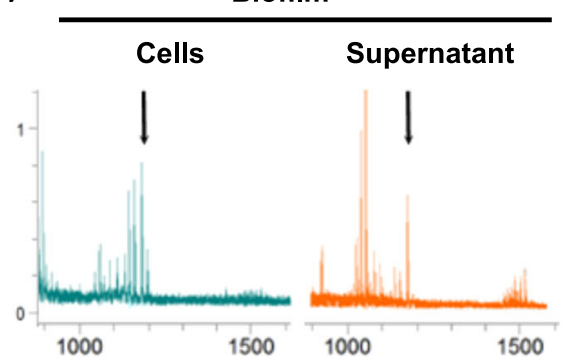

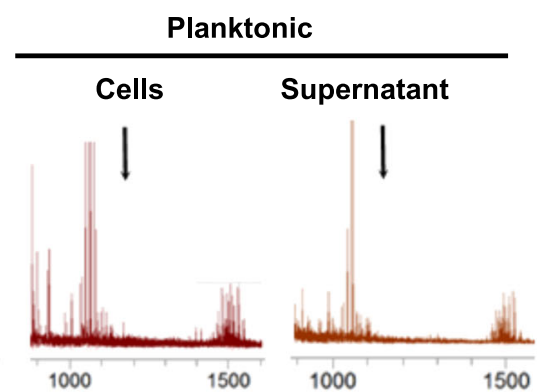

Fig. 4 Cells in a biofilm produce more antimicrobials. a Scheme of the genes for the biosynthesis of thiocillin are overexpressed in biofilm cells (BC5094-BC5070). Genes with no variation in expression level are shown in gray color. b 3D structure of the thiocillin molecule. c Detail of the traces from HPLC-MS-MS (TOF-TOF) of cells and supernatants of $48 \mathrm{~h}$ aged cultures. Biofilms were collected and suspended in PBS, separating cells from the supernatant after centrifugation. Culture medium was centrifuged to separate floating cells from the supernatant. Samples were purified with C8 ZipTip ${ }^{\circledR}$ (Merck) previous to analysis. Black arrows indicate the positions of the thiocillin peaks. See the supplemental material for the complete spectra (Supplemental Fig. S5). 
A)
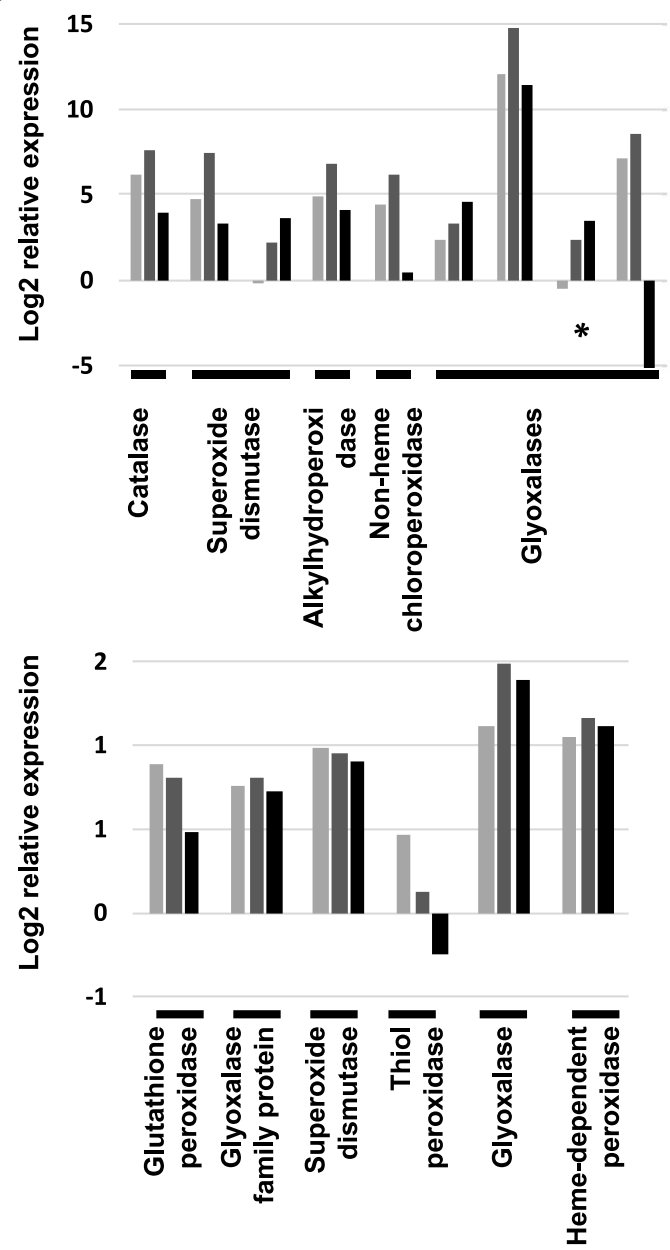

B)

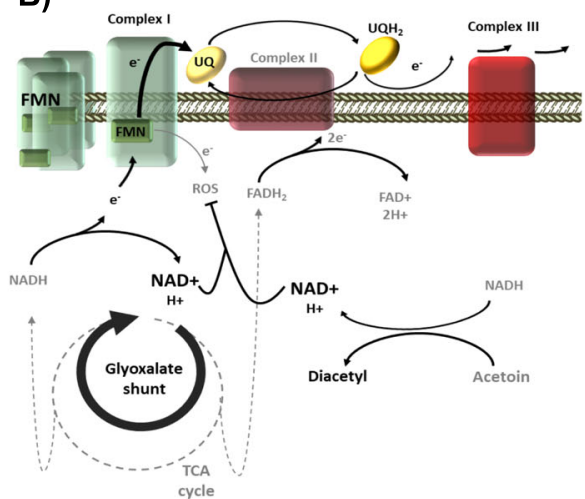

C)

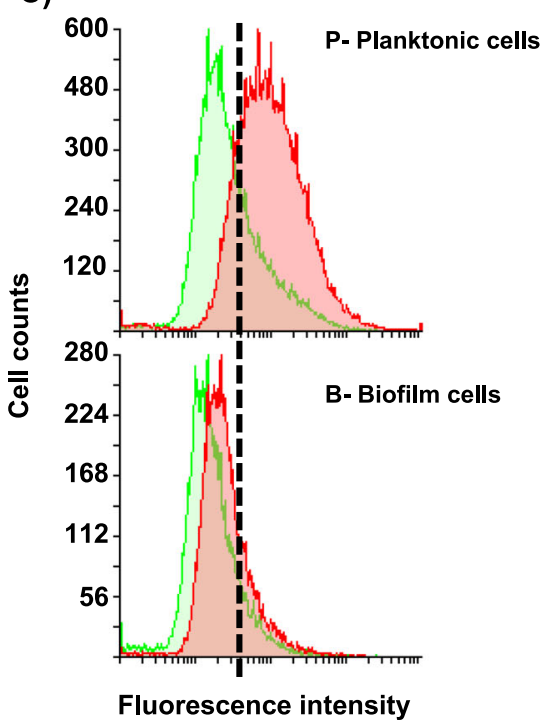

D)

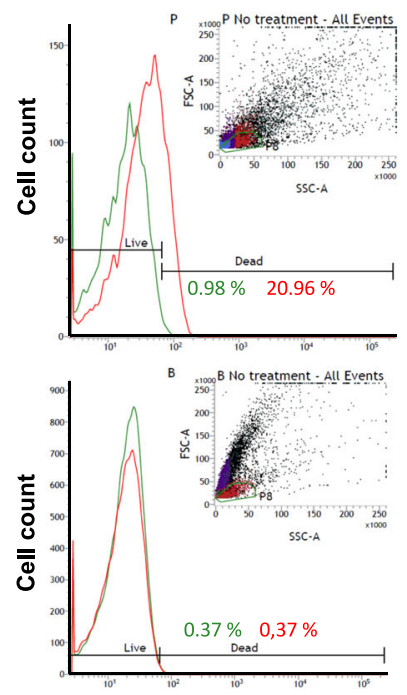

Fluorescence (Propidium iodide)
P- Planktonic cells

\begin{tabular}{|lll}
\hline Sample & Events & $\%$ \\
\hline $\mathrm{P}$ no treatment:live & 5230 & 99.02 \\
$\mathrm{P}$ no treatment:dead & 52 & 0.98 \\
\hline $\mathrm{P} 0.1 \mathrm{mM} \mathrm{H}_{2} \mathrm{O}_{2}$ :live & 4856 & 79.28 \\
\hline $\mathrm{P} 0.1 \mathrm{mM} \mathrm{H}_{2} \mathrm{O}_{2}$ : dead & 1284 & 20.96 \\
\hline
\end{tabular}

B- Biofilm cells

\begin{tabular}{|lll}
\hline Sample & Events & $\%$ \\
\hline B no treatment:live & 29412 & 99.66 \\
B no treatment:dead & 110 & 0.37 \\
\hline B $0.1 \mathrm{mM} \mathrm{H}_{2} \mathrm{O}_{2}:$ live & 28320 & 99.66 \\
\hline B $0.1 \mathrm{mM} \mathrm{H}_{2} \mathrm{O}_{2}:$ dead & 106 & 0.37 \\
\hline
\end{tabular}

In nature, biofilms are produced in a multispecies way, in continuous competition and dealing with the antimicrobials produced by other species. We reasoned that evolution selected individuals triggering antimicrobial resilience together with the pool of biofilm-related genes, including ROS detoxification and changes to prevent ROS production. We evaluated the major ability of biofilm cells to deal with oxidative stress, introduced by our RNA-seq analysis, in two complementary experiments. First, flow cytometry analysis revealed higher intrinsic oxidative stress of planktonic cells (Fig. 5c, top green histogram) compared to biofilm 
Fig. 5 Cells in a biofilm trigger the machinery dedicated to scavenging reactive oxygen species. a Expression pattern of ROS detoxification enzymes in biofilm compared to floating cells at $24 \mathrm{~h}$ (light gray), $48 \mathrm{~h}$ (gray), and $72 \mathrm{~h}$ (black) based on RNA-seq (top) or iTRAQ (bottom) analysis. b Scheme of the metabolic rearrangement to reduce ROS production from the electron leakage of the flavin mononucleotide (FMN). Overexpression of the complex I and FMN, reduction of the $\mathrm{NADH} / \mathrm{NAD}^{+}$ratio degrading acetoin, activation of the glyoxylate shunt, and reduction of the ubiquinone (UQ) saturation lead to release the fully reduced state of the FMN, preventing electron leakage. c Oxidative stress of planktonic (top) and biofilm (bottom) cells of $B$. cereus of $48 \mathrm{~h}$. The green histogram corresponds to the intrinsic oxidative stress and the red histogram the oxidative stress induced by $400 \mathrm{mM}$ cumene hydroperoxide treatment. d ROS survival assay of planktonic (top) and biofilm (bottom) cells of $48 \mathrm{~h}$ aged after treatment with $0.1 \mathrm{mM} \mathrm{H}_{2} \mathrm{O}_{2}$ solution for $30 \mathrm{~min}$. Cell viability was measured by cell staining with Live and Dead $^{\circledR}$ and analysis with flow cytometry comparing each untreated population (green lines) with treated biofilm or planktonic cells (red lines). Cell population considered is marked with green boundaries (P8) in the events graph (insets).

cells (Fig. $5 c$, top green histogram), as well as the major ability of the biofilm cells to detoxify the ROS generated by the highly oxidative agent cumene hydroperoxide (Fig. 5c, red histograms). Second, to test the major predicted resilience of biofilm cells than planktonic cells to damage induced by ROS stress, we evaluated the rate of mortality of the two populations at $48 \mathrm{~h}$ aged after treatment with $0.1 \mathrm{mM} \mathrm{H}_{2} \mathrm{O}_{2}$ solution. After $30 \mathrm{~min}$ of exposure, planktonic cells showed around $20 \%$ of mortality while the biofilm population was unaffected (Fig. 5d), confirming the upregulation of the functionality revealed by the transcriptomic and proteomic results. A comparable cell numbers of each subpopulation was initially used for the treatment, however, we found a reduction in the number of cell counts in the planktonic subpopulation in the flow cytometry analysis, a fact that might be altering the real effect of oxidative stress and should be addressed in future works.

\section{Planktonic cells express much higher levels of virulence factors}

In the interaction with hosts, bacterial cells must overcome their diversified immune responses, and this is achievable with the gain of so-called virulence factors. We have found two factors which might complementarily contribute to the survival of bacterial cells despite the host immune system. One factor is a specific betalysine acetyltransferase $\left(B C 2249^{*}\right)$, which may confer resistance to beta-lysine, an antibacterial compound produced by platelets during coagulation that induces lysis in many Gram-positive bacteria. ${ }^{48}$ The other factor is the immune Inhibitor A (InhA) precursor, which is a bacterial enzyme able to (i) digest attacins and cecropins, two classes of antibacterial humoral factors in insects, ${ }^{49}$ (ii) cleave hemoglobin and serum albumin, two natural sources of amino acids which are thus relevant to bacteremia ${ }^{50}$; and (iii) InhA1 is a key effector implicated in the liberation of spores from macrophages. ${ }^{51}$ Consistent with the biofilm resilience and the enhancement of sporulation within the biofilm, the three InhA paralogues $\left(B C 0666^{x}, B C 1284^{*}, B C 2984^{*}\right)$ found in the genome of $B$. cereus are upregulated in biofilm. The expression of InhA2 (BC0666) is dependent of PlcR, which is downregulated, what is contradictory. However, iTRAQ results indicated that $B C 0666$ quantity of protein was reduced, reinforcing the rationale of running additional and complementary analysis as iTRAQ to confirm the findings of RNA-seq.

In addition to these changes in gene expression leading to resilience of $B$. cereus biofilms against the host immune system, $B$. cereus biofilm cells seems to reduce their toxicity to host. This bacterium possesses a variety of toxins: cytotoxin $\mathrm{K}$ (cytK), nonhemolytic enterotoxin (NHE), enterotoxin C (EntC), hemolysin III, hemolysin $\mathrm{BL}(\mathrm{HBL})$, haemolysin XhIA, invasins (three collagenases and a phospholipase $\mathrm{C}$ ), and thiol-activated cytolysin I. These toxins and proteases and its positive regulator PlcR are strongly downregulated in biofilm-associated cells, except for hemolysin III, which is independent of $\mathrm{PlcR},{ }^{52}$ To demonstrate that floating cells are more prone than biofilm-associated cells to attack the host, both bacterial cell types were isolated and tested for their toxicity potential toward human HeLa and MDA cell lines in toxicity assays (Fig. 6, Supplementary Fig. 7 and Supplementary Movies). As expected from our analysis, floating cells, which possess an enhanced machinery for toxin production, killed human cells much faster than biofilm-associated cells did, an effect seen using different bacteria:cell ratios in both cell lines (Supplementary Fig. 7). These enterotoxins are labile and do not survive stomach passage, injuring the hosts only when they are produced within the intestine. Thus, it might be reasonably suggested that floating cells and germinating spores of $B$. cereus in the transit through the intestinal track are prone to produce the toxins; and biofilm cells are more oriented to defense and inhibition of the immune response. The strategy used by floating cells seems to be less oriented to survive the host attack, redirecting all the efforts to produce toxins and other virulence factors with the aim of achieving a fast, aggressive and effective attack to the host, as reported in some clinical cases in which patients died within several hours after the intake of contaminated food. ${ }^{53}$

Planktonic and sessile cells coordinately attack and defend

In our experimental setup, biofilm and floating cells coexist, which led us to explore the existence of metabolic specialization and possible connections between these two populations of cells at $24 \mathrm{~h}$, when each population initiates the differentiation process. Among the genes showing differential expression between floating and biofilm cells, 862 showed predicted associations in the STRING database with a confidence threshold $>500$, which were used to build a primary network using the STRINGdb and iGraph R packages (Fig. 7). Using the Betweenness algorithm (Newman and Girvan), we found 16 subnetworks with a minimum of ten genes. We observed that the majority of modules contain genes either more highly expressed in the biofilm (red nodes) or in floating cells (blue nodes), corresponding to specific functions described previously, which clearly belong to biofilm or planktonic cells. Two examples of clusters supported the validity of our analysis, showing enrichment of expected functions for biofilm or floating cells, respectively: Cluster 2 contains genes associated with sporulation, a developmental process that is upregulated in biofilms (Cluster 2: Fig. 7 and Supplementary Table 6). Cluster 3 is involved in the bacterial flagella assembly and chemotaxis, a function that is predominantly activated in floating cells (Cluster 3: Fig. 7c and Supplementary Table 7). Clusters containing mixed elements (red for biofilm and blue for floating cells) were ranked by size and functionally analyzed to identify pathways that could be existent in both cell populations. The mixed Cluster 1 is composed of 83 genes (52 planktonic and 32 biofilm) (Supplementary Table 3). A total of 9 KEGG pathways are included in this cluster (Supplementary Table 4). Within these global metabolic groups, the integration of genes from each population is specifically outstanding for: (i) the TCA cycle and 2-oxocarboxylic acid metabolism, with the floating and biofilm genes clearly divided into different sub-routes within the same metabolic pathways (Supplementary Figs. 8 and 9) and (ii) three metabolic KEGG pathways containing $85 \%$ of genes that have known functions (Cluster 1 Fig. 7 and Supplementary Table 3-5) and that are prominently dedicated to secondary metabolism and antibiotic biosynthesis. 


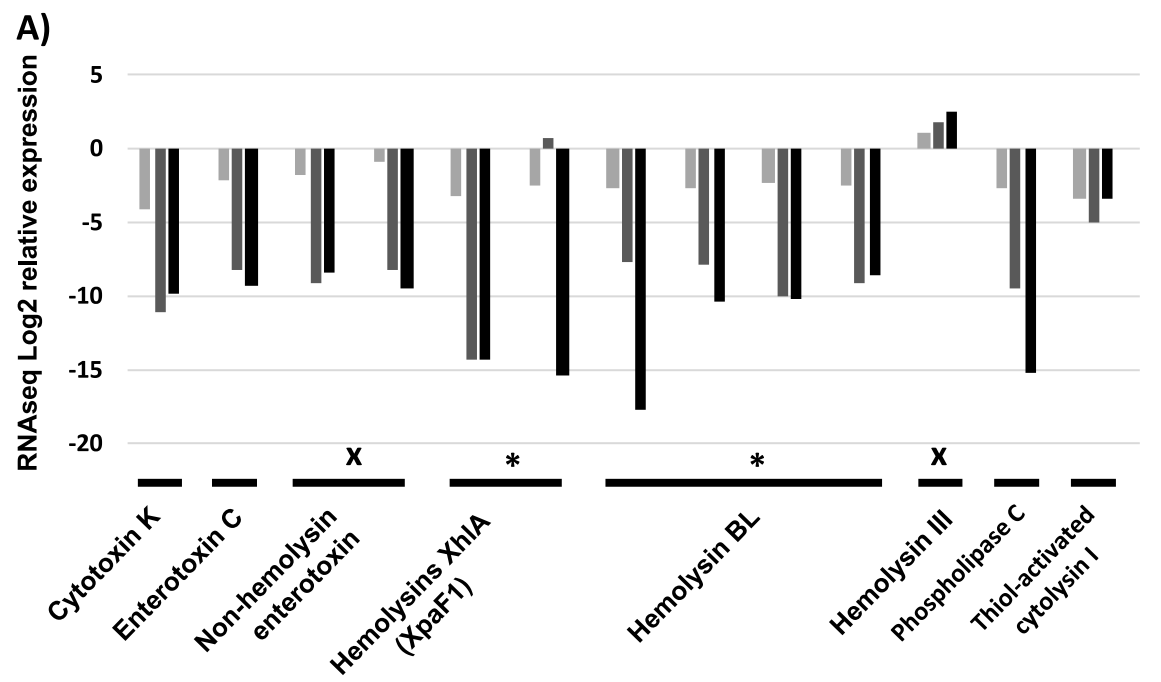
B) Toxicity on Hela cells
$+4^{*} 10^{7} \mathrm{ucf} / \mathrm{ml}$

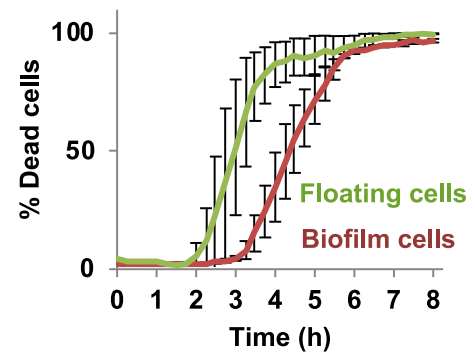

C)

Toxicity on MDA cells $+2^{*} 10^{7} \mathrm{ucf} / \mathrm{ml}$

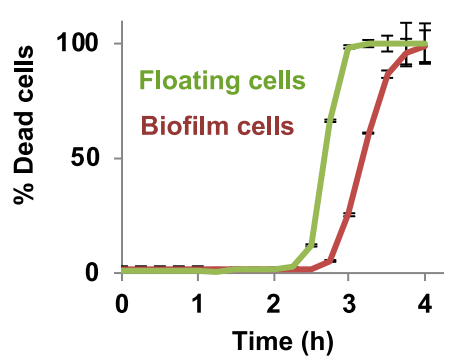

D)

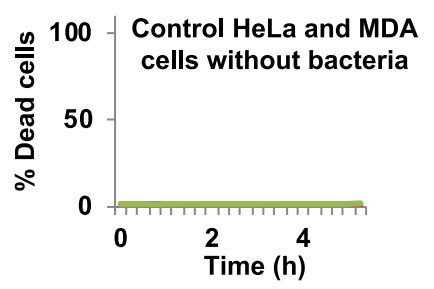

E)

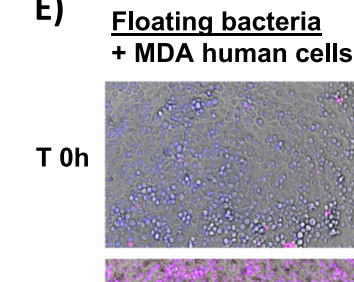

Biofilm bacteria + MDA human cells

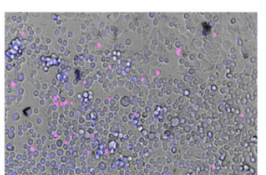

T $3 h$
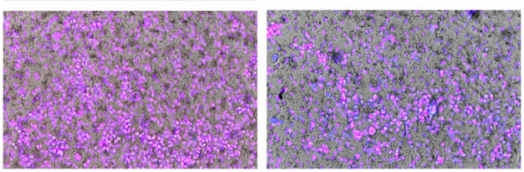

Dead cells (Propidium iodide)

Nucleus (Hoechst)

Fig. 6 Cells in a biofilm are less aggressive to the host than floating cells are. a Expression pattern of toxins in a biofilm compared to floating cells at $24 \mathrm{~h}$ (light gray), $48 \mathrm{~h}$ (gray), and $72 \mathrm{~h}$ (black) (RNA-seq data). Data confirmed by iTRAQ results are marked with a star. Data in conflict with iTRAQ data are marked with a cross. b, c Toxicity assay of floating (green line) or biofilm (red line) cells of $48 \mathrm{~h}$ bacterial cultures against HeLa and MDA cell lines cultures without antibiotics. Error bars indicate SD $(n=12)$. d Negative control of the toxicity assay. e Micrographs of the toxicity assay after $3 \mathrm{~h}$ of incubation. Dead cells (pink) are stained with propidium iodide. Nuclei are stained with Hoechst (blue). (See the attached Supplementary Movies of cell death progress in the Supplementary data and Supplementary Fig. 7).

All the information obtained from our study have been integrated into a model which collects the most distinctive features characterizing floating or biofilm-associated cells (Fig. 8). Biofilm-associated cells seem to direct the energy to the synthesis of the extracellular matrix and anatomical changes conducive to individual resilience to external aggressions. This specialization is complemented by the deviation of the metabolism to the synthesis of secondary metabolites, some of which might mediate the interaction with competitors at short distances from or even in close contact with the biofilm (Fig. 6b). However, floating cells are metabolically predisposed to colonize new niches and are also more aggressive in terms of pathogenicity, showing an increased production of toxins, conducive to the acquisition of more nutrients. In summary, this study redefines our view of $B$. cereus biofilm versus floating cells and goes further, mapping how deep the physiological and functional changes are in the switch from one lifestyle to the other.

\section{METHODS}

Bacterial strains and culture conditions

The bacteria used in this study was B. cereus ATCC14579 obtained from the Spanish collection of type strains (CECT148). The mediums used to culture bacteria were LB agar and liquid TyJ broth [(1\% tryptone, OXOID), $0.5 \%$ yeast extract (OXOID), $0.5 \% \mathrm{NaCl}_{1} 10 \mathrm{mM} \mathrm{MgSO}_{4}$, and $0.1 \mathrm{mM} \mathrm{MnSO}_{4}$ ] were used for bacterial cultures. Bacteria were routinely streaked from $-80^{\circ} \mathrm{C}$ stocks onto LB agar and incubated at $24 \mathrm{~h}$ at $30^{\circ} \mathrm{C}$ before each experiment. 

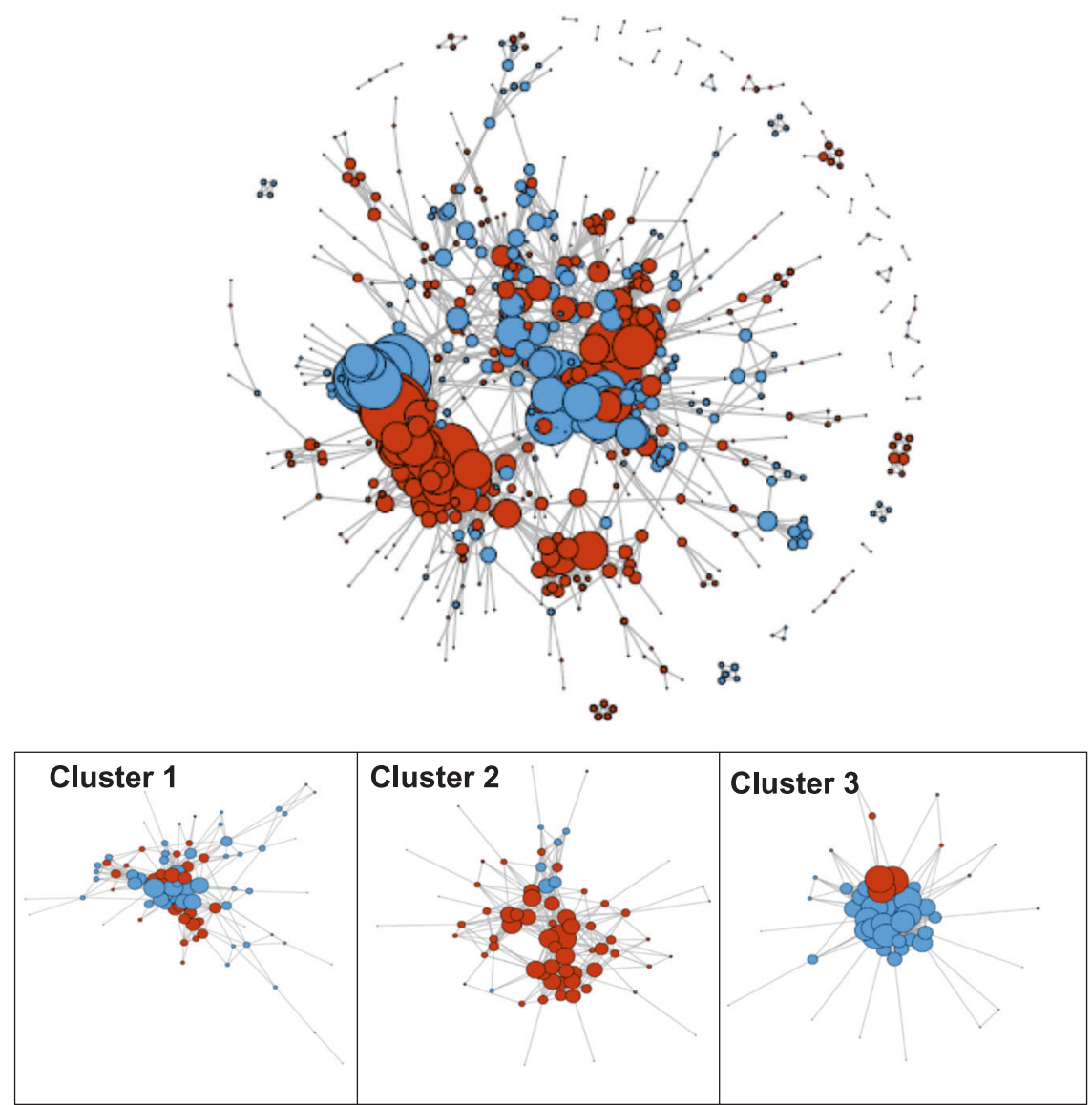

Fig. 7 Specialization of biofilm and floating cells in distinct but coordinated metabolic activity. Networks formed by the differentially expressed (DE) genes and the functional associations between them. Each node represents a gene significantly DE between planktonic and biofilm samples at $24 \mathrm{~h}$; each edge represents an association between two genes according to the STRING database, as described in the Methods. Red nodes represent genes more highly expressed in the biofilm samples; blue genes represent genes more highly expressed in the planktonic samples. To the left is the global network formed by all DE genes. To the right, Clusters $1-3$ represent subsets of the global network, obtained using the module detection method. Cluster 1 contains a mix of genes from both populations (floating and biofilm cells) and are dedicated to global metabolic pathways. Cluster 2 contains genes related to sporulation and are mostly from biofilm cells. Cluster 3 contains genes dedicated to flagellum assembly and chemotaxis and are mostly from floating cells.

For biofilm experiments, several colonies were suspended in $1 \mathrm{ml}$ of TyJ broth, and the final OD600 was adjusted to one. One milliliter of TyJ in 24well plates was inoculated with $10 \mu \mathrm{l}$ of the bacterial cell suspension. Only central lines of the wells in the plates where used for culture. Plates were incubated at $30^{\circ} \mathrm{C}$ for 24,48 , and $72 \mathrm{~h}$.

Cell sampling, RNA isolation and whole-transcriptome sequencing Biofilm, a bacterial biomass adhered to the walls of the wells, was collected with sterile cotton swabs, suspended in $1 \mathrm{ml}$ of TyJ, and centrifuged at $12,000 \times g$ for $10 \mathrm{~s}$; the pellet was immediately frozen in liquid nitrogen after discarding the supernatant. As the amount of biofilm formed change over time, collections from 2-8 wells were merged to reach a feasible number of cells for further RNA isolation. For floating cell sampling, $250-500 \mu \mathrm{l}$ of culture was collected from several wells without disturbing the submerged biofilm, mixed in a $2 \mathrm{ml}$ tube, and centrifuged at $12,000 \times g$ for $10 \mathrm{~s}$; the pellet was immediately frozen in liquid nitrogen after discarding the supernatant. Samples were stored at $-80^{\circ} \mathrm{C}$. Samples were recovered from $-80^{\circ} \mathrm{C}$, and cold beads were added to each tube and $900 \mu \mathrm{l}$ of TRI-reagent (Invitrogen), followed by bead beating in a tissue lyser immediately for $1 \mathrm{~min}$. The samples were placed $3 \mathrm{~min}$ at $55^{\circ} \mathrm{C}$. After addition of $200 \mu \mathrm{l}$ chloroform, tubes were vortexed for $10 \mathrm{~s}$, incubated 2-3 $\mathrm{min}$ at room temperature and centrifuged at $12,000 \times \mathrm{g}$ for $10 \mathrm{~min}$ at $4{ }^{\circ} \mathrm{C}$. The upper phase was mixed with $500 \mu \mathrm{l}$ ice-cold isopropanol for RNA precipitation, incubated for $10 \mathrm{~min}$ at RT, and centrifuged at $12,000 \times g$ for $10 \mathrm{~min}$ at $4{ }^{\circ} \mathrm{C}$. The pellet was washed with $75 \%$ ethanol, centrifuged twice to remove all supernatant and air-dried for $5 \mathrm{~min}$. The pellet was suspended in $20 \mu \mathrm{l}$ DEPC water (Carl Roth $\mathrm{GmbH}$ ). DNA was removed using RQ1 DNase treatment (Promega) with a RiboLock RNase inhibitor (Thermo) following the product instructions. After digestion, $400 \mu \mathrm{l}$ DEPCMQ water, $250 \mu \mathrm{l}$ phenol, and $250 \mu \mathrm{l}$ chloroform were added to the samples, vortexed for $5 \mathrm{~s}$ and centrifuged at $15,000 \times g$ for $15 \mathrm{~min}$ at $4{ }^{\circ} \mathrm{C}$. The supernatant was mixed with $1 \mathrm{ml}$ ice-cold $10 \%$ ethanol and $50 \mu \mathrm{l} 3 \mathrm{M}$ sodium acetate $\mathrm{pH}$ 5.2. The mixture was incubated at least $30 \mathrm{~min}$ at $-20^{\circ} \mathrm{C}$ and then centrifuged at $15,000 \times g$ for $15 \mathrm{~min}$ at $4{ }^{\circ} \mathrm{C}$. The pellets were washed twice with $75 \%$ ethanol and centrifuged at $15,000 \times g$ for 5 min at $4{ }^{\circ} \mathrm{C}$. After spinning the tubes to retire as much of the supernatant as possible, pellets were air-dried at RT for $5 \mathrm{~min}$ and suspended in $20 \mu \mathrm{l}$ DEPC water (Carl Roth $\mathrm{GmbH}$ ). Samples were sent as two biological replicates to the PrimBio Research Institute (Exton, PA, USA), at which the $16 \mathrm{~S} / 23 \mathrm{~S}$ rRNA removal with the Ribo-Zero kit, mRNA quality control (QC), cDNA library preparation, library $\mathrm{QC}$, template preparation, template $\mathrm{QC}$, and RNA-sequencing on an Illumina platform was performed.

Data analysis of the whole transcriptomes

After trimming the raw RNA-seq reads (PE150 (paired-end $150 \mathrm{bp}$ )) from the adapter sequences, reads were mapped against the $B$. cereus ATCC 14579 genome sequence. The RPKM (reads per kilo base per million mapped reads) table was generated, and differential gene expression analyses were carried out with the webserver pipeline T-Rex ${ }^{54}$ on the Genome2D webserver (http://genome2d.molgenrug.nl/). The significance threshold was defined by a $p$-value of $<0.05$ and a fold-change of $>2$ ("TopHits" in T-REx). The annotation was done against B. cereus ATCC14579 genome using the annotation tool of the Genome-2D webserver. Cluster of orthologous groups (COG) analysis was performed using the Functional 


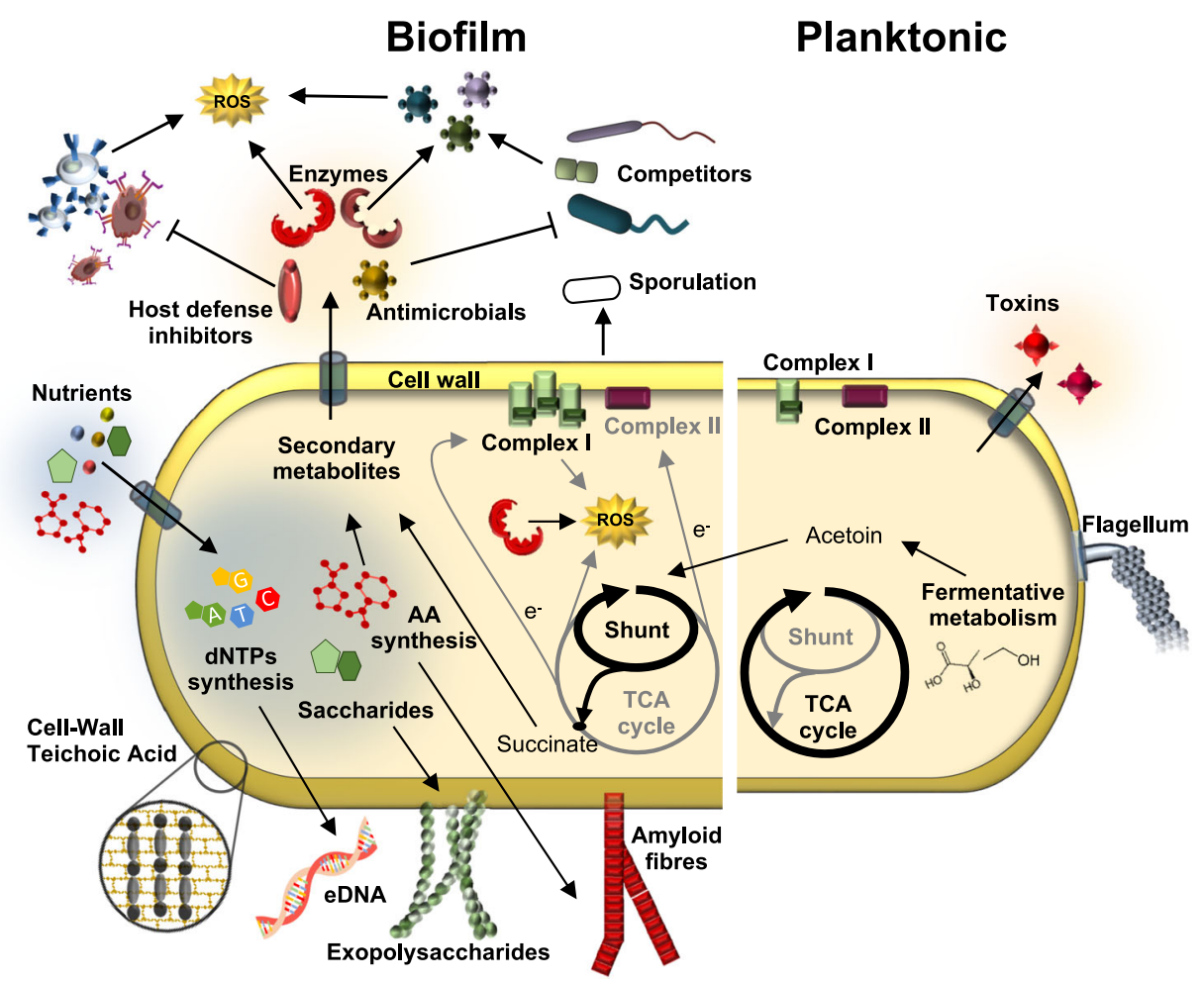

Fig. 8 Model of offence and defense of floating cells and cells in the air-liquid interphase biofilm. Major changes differentiate the biofilm from floating cells. Biofilm cells manifest a collection of physiological and morphological changes leading to protection mediated by the increase in the cell wall thickness, flagellum disassembly, the expression of inhibitors of the host defense and antimicrobial resistance genes, synthesis of the extracellular matrix (eDNA, exoplysaccharides and amyloid fibres), overexpression of the anti-ROS machinery including metabolic changes, or the triggering of sporulation. These changes coordinate with an offensive action against competitors, driven by the production of antimicrobials. In contrast, floating cells tend to be more active metabolically and more aggressive in the interaction with hosts, overexpressing a pull of toxins.

Analysis Tools of the T-REx pipeline. The RNA-seq data from this study have been submitted to the NCBI Gene Expression Omnibus (GEO; http://www. ncbi.nlm.nih.gov/geo/).

BAGEL $3^{55}$ and antiSMASH ${ }^{56}$ were used to identify secondary metabolite synthesis regions in the genome of $B$. cereus ATCC 14579. To compare the behavior of sporulation genes across the maturation progress of the biofilm, we used $k$-means clustering (an algorithm that groups similar data into arbitrary $\mathrm{k}$ clusters) with the STEM (Short Time-series Expression Miner) software package.

\section{Proteomic analysis}

Biofilm and floating cells were separated following the method described above. Samples were sent in triplicate to the Proteomic Facility of the Centro Nacional de Biotecnología CSIC (Spain) for Isobaric Tags for Relative and Absolute Quantitation (iTRAQ). Protein digestion and tagging with a TMTsixplex $^{\mathrm{TM}}$ reagent was performed as follows: The total protein concentration was determined using a Pierce $660 \mathrm{~nm}$ protein assay (Thermo). For digestion, $40 \mu \mathrm{g}$ of protein from each condition was precipitated by the methanol/chloroform method. Protein pellets were suspended and denatured in $20 \mu \mathrm{l} 7 \mathrm{M}$ urea/2 M thiourea/100 mM TEAB, $\mathrm{pH} 7.5$, reduced with $2 \mu \mathrm{L}$ of $50 \mathrm{mM}$ Tris(2-carboxyethyl) phosphine (TCEP, SCIEX), $\mathrm{pH} 8.0$, at $37^{\circ} \mathrm{C}$ for $60 \mathrm{~min}$ and followed by the addition of $1 \mu \mathrm{L}$ of $200 \mathrm{mM}$ cysteine-blocking reagent (methyl methanethiosulfonate (MMTS, Pierce) for $10 \mathrm{~min}$ at room temperature. Samples were diluted up to $140 \mu \mathrm{L}$ to reduce the urea concentration with $25 \mathrm{mM}$ TEAB. Digestions were initiated by adding $2 \mu \mathrm{g}$ of sequence grade-modified trypsin (Sigma-Aldrich) to each sample at a ratio of 1:20 (w/w); the samples were then incubated at $37^{\circ} \mathrm{C}$ overnight on a shaker. Sample digestions were evaporated to dryness in a vacuum concentrator. The resulting peptides were subsequently labeled using a TMT-sixplex Isobaric Mass Tagging Kit (Thermo Scientific, Rockford, IL, USA) according to the manufacturer's instructions, as follows: 126: 1B-24h (Biofilm 24h); 127: 1B-48 h (Biofilm 48 h); 128: 1B-72 h (Biofilm $72 \mathrm{~h}$ ); 129: 1P-24h (Planktonic 24h). After labeling, the samples were pooled, evaporated to dryness and stored at $-20^{\circ} \mathrm{C}$ until the LC-MS analysis.

For liquid chromatography and mass spectrometry analysis, $1 \mu \mathrm{g}$ of the labeled protein mixture was subjected to 1D-nano LC ESI-MS/MS analysis using a nanoliquid chromatography system (Eksigent Technologies NanoLC Ultra 1D plus, SCIEX, Foster City, CA) coupled to a high-speed Triple TOF 5600 mass spectrometer (SCIEX, Foster City, CA) with a Nanospray III source. The analytical column used was a silica-based reversed-phase ACQUITY UPLC ${ }^{\circledR}$ M-Class Peptide BEH C18 Column, $75 \mu \mathrm{m} \times 150 \mathrm{~mm}, 1.7 \mu \mathrm{m}$ particle size and $130 \AA$ pore size (Waters). The trap column was C18 Acclaim PepMap ${ }^{\text {TM }} 100$ (Thermo Scientific), $100 \mu \mathrm{m} \times$ $2 \mathrm{~cm}, 5 \mu \mathrm{m}$ particle diameter, $100 \AA$ pore size, switched on-line with the analytical column. The loading pump delivered a solution of $0.1 \%$ formic acid in water at $2 \mu \mathrm{l} / \mathrm{min}$. The nanopump provided a flow-rate of $250 \mathrm{nl} /$ min and was operated under gradient elution conditions. Peptides were separated using a gradient of 250 min ranging from $2 \%$ to $90 \%$ mobile phase B (mobile phase A: $2 \%$ acetonitrile, $0.1 \%$ formic acid; mobile phase B: $100 \%$ acetonitrile, $0.1 \%$ formic acid). The injection volume was $5 \mu$ l.

Data acquisition was performed with a TripleTOF 5600 System (SCIEX, Foster (ity, CA). Data were acquired using an ion spray voltage floating (ISVF) 2300 V, curtain gas (CUR) 35, interface heater temperature (IHT) 150, ion source gas 1 (GS1) 25, declustering potential (DP) $150 \mathrm{~V}$. All data were acquired using information-dependent acquisition (IDA) mode with Analyst TF 1.7 software (SCIEX, Foster City, CA). For IDA parameters, a 0.25 s MS survey scan in the mass range of 350-1250 Da were followed by $30 \mathrm{MS} / \mathrm{MS}$ scans of $150 \mathrm{~ms}$ in the mass range of 100-1800. Switching criteria were set to ions greater than a mass-to-charge ratio $(\mathrm{m} / \mathrm{z})$ of 350 and smaller than $\mathrm{m} / \mathrm{z} 1250$ with a charge state of 2-5 and an abundance threshold of more than 90 counts (cps). Former target ions were excluded for $20 \mathrm{~s}$. An IDA rolling collision energy (CE) parameters script was used for automatically controlling the CE.

For data analysis and protein identification, the mass spectrometry data obtained were processed using PeakView ${ }^{\circledR} 2.2$ software (SCIEX, Foster City, CA). Raw data file conversion tools generated mgf files, which were also searched against the $B$. cereus protein database from Uniprot (database 
state June-August 2016), containing 40530 protein-coding genes that included their corresponding reversed entries using four different search engines (Mascot, OMSSA, X!TANDEM and MyriMatch). Search parameters were set as follows: enzyme, trypsin; allowed missed cleavages, 2; methylthio (C) as a fixed modification and TMT-6plex (N-term, K, Y), acetyl (protein N-term), oxidation (M), Gln->pyro-Glu (N-term $\mathrm{Q}$ ) and Glu->pyroGlu (N-term E) as variable modifications. The peptide mass tolerance was set to $\pm 25 \mathrm{ppm}$ for precursors and $0.02 \mathrm{Da}$ for fragment masses. The confidence interval for protein identification was set to $\geq 95 \%(p<0.05)$, and only peptides with an individual ion score above the $1 \%$ false discovery rates (FDR) threshold were considered correctly identified. A 5\% quantitation FDR threshold was estimated to consider the significant differentially expressed proteins.

\section{Network creation, clustering, and functional analysis}

Data on potential pairwise associations between Bacillus cereus genes were downloaded from the STRING database ${ }^{57}$ using the STRINGdb Bioconductor package for $\mathrm{R}$. This resource comprises data from multiple sources related to direct interactions, both direct and inferred through homology, and predicted associations, made through a variety of algorithms using different data sources. These pairwise associations were then used to build a network between all genes that showed differential expression between biofilm and floating samples, using iGraph, visualized using Cytoscape. ${ }^{58}$ This network was then clustered using the edge betweenness algorithm ${ }^{59}$ to find modules of genes with a high degree of connectivity between them, compared to connections to genes outside the module. The DAVID tool $^{60}$ was employed for functional annotation of the genes of each cluster. More specifically, it was used to look for enrichment of biological processes using the $\mathrm{GO}^{61}$ and pathways using the KEGG database. ${ }^{62}$ When the genes in a cluster led to the enrichment of very similar processes/pathways in both GO and KEGG, the results of only one of these two sources were selected to avoid functional annotation redundancy, due to what is essentially the same process being annotated more than once for a given cluster. When the results were different, all processes/pathways were used.

\section{Mass spectrometry analysis for thiocillin detection}

Thiocillin detection was analyzed using HPLC-MS-MS (Ultraflex TOF-TOF, Bruker) of cells and supernatants of $48 \mathrm{~h}$ cultures of B. cereus in TyJ medium incubated at $28^{\circ} \mathrm{C}$ without shaking. The biofilm was collected and thoroughly suspended in PBS and then centrifuged at $12,000 \times g$ to separate cells from the supernatant. Culture medium was centrifuged to separate floating cells from the supernatant. Previous to analysis, the samples were purified with C8 ZipTip ${ }^{\circledR}$ (Merck) to discard salts. To perform MS-MS, a low molecular weight matrix was used.

\section{Construction of mutants in $B$. cereus}

B. cereus eps 1 or eps 2 mutant were obtained by electroporation ${ }^{63}$ using the plasmid pMAD, harboring a fragment to delete the genes $B C 5279-B C 5274$ or genes $B C 1583-B C 1591$, respectively, by double recombination. The construct was created by joining PCR using specific primers (listed in Table S8) to amplify flanking regions of $1800-2000 \mathrm{pb}$. In the first step, regions flanking the target genes were amplified separately, purified, and used for the joining PCRs. These PCR products were digested and cloned into the pMAD vector digested with the same enzymes. The resulting suicide plasmids were used to transform $B$. cereus electrocompetent cells as follows. Electroporation was performed with $10 \mu \mathrm{g}$ of plasmids in $100 \mu \mathrm{L}$ of electrocompetent $B$. cereus in $0.2-\mathrm{cm}$ cuvettes using the following electroporation parameters: voltage $1400 \mathrm{kV}$, capacitance $25 \mu \mathrm{F}$, resistance $400 \Omega$. After electroporation, cells were incubated in LB for $5 \mathrm{~h}$, and then seeded in LB medium supplemented with X-Gal and erythromycin for $72 \mathrm{~h}$ at $30^{\circ} \mathrm{C}$. Blue colonies were selected and streaked to trigger allele replacement. Finally, white colonies that were sensitive to MLS (Macrolide, Lincosamide and Streptogramin; erytromicin was used for selection) were selected, and deletion of the target gene was verified by colony PCR analysis and sequencing of the amplicons.

Complementation of eps 2 mutant was done using the replicative plasmid pUTE973 (kindly provided by Theresa M. Koehler, University of Texas) harboring the construction of $P_{I P T G}$-eps2. The primers used to amplify the genomic region were eps2.Fw TITTGTCGACGATGAAGAGATACGAGGAATTGG and eps2.Rv TाTGCATGCGTTGAACCAAATTACAATCTC and the fragment was cloned in the Sall and Sphl cut of pUTE973 downstream of the $P_{\text {iptg }}$ promoter. The activity of this promoter was triggered using a $1 \mathrm{mM}$ of IPTG solution.
Evaluation of bacterial cell wall thickness

Biofilm and floating cells were separated following the method described above and fixed in $2 \%$ glutaraldehyde. Post fixation was performed with $1 \%$ osmium tetroxide in $0.1 \mathrm{M}, \mathrm{pH} 7.4$ phosphate buffer, following dehydration in an acetone gradient at $4{ }^{\circ} \mathrm{C}: 30 \%, 50 \%, 70 \%$, and $90 \%$. A step for in bloc staining with $1 \%$ uranyl acetate in $50 \%$ cold acetone was included after the $50 \%$ step, leaving the samples overnight at $4{ }^{\circ} \mathrm{C}$. Dehydration was continued with serial incubations in absolute acetone and propylene oxide at room temperature. The embedding in Spurr's resin was made following different steps that combined Spurr's resin:propylene oxide at 1:1, 3:1 (overnight) and two changes in pure resin (the second one, overnight). Finally, samples were embedded in pure resin at $70^{\circ} \mathrm{C}$ for 3 days. Ultrathin sections were visualized in a JEOL JEM-1400 transmission electron microscope with a high-resolution camera (Gatan ES1000 W). The analysis was done using ImageJ-Fiji software over 40 images of each sample and 6-10 measurements over each picture using only circular cell sections to avoid the effect of a tilted sectioning.

Analysis of oxidative stress and reactive oxygen species (ROS) survival assay

Biofilm and planktonic populations were collected in $\mathrm{NaCl}$ buffer $(0.5 \mathrm{~g} / \mathrm{L})$, mild sonicated for $30 \mathrm{~s}$ at $30 \%$ intensity to separate cells. To determine the intrinsic oxidative stress of cells of each subpopulation, the CellROX ${ }^{\mathrm{TM}}$ Green Reagent (Invitrogen ${ }^{\mathrm{TM}}$ ) was used at a $2.5 \mu \mathrm{M}$ concentration. The cells were alternatively treated with cumene hydroperoxide $(400 \mu \mathrm{M})$ an hour at $37^{\circ} \mathrm{C}$. All samples were incubated with the reagent for $30 \mathrm{~min}$ at $37^{\circ} \mathrm{C}$. The cells were washed three times in PBS, and then were sonicated twelve times at 30\% intensity. Samples were fixed with paraformaldehyde at $4 \%$ diluted in PBS. Finally, the cells were analyzed in flow cytometry (Beckman Coulter Galios), using a $488 \mathrm{~nm}$ laser for excitation and $532 \mathrm{~nm}$ for emission.

To determine the rate of cell death, the cells of each subpopulation was exposed to $0.1 \mathrm{mM}$ of $\mathrm{H}_{2} \mathrm{O}_{2}$ for $30 \mathrm{~min}$. $\mathrm{H}_{2} \mathrm{O}_{2}$ was retired by centrifugation and cells were suspended again in $\mathrm{NaCl}$ buffer. Before cytometry analysis (BD FACSVerse ${ }^{\circledast}$ equipment), cells received a sonication bath for $3 \mathrm{~min}$. Cell deadness was assayed using Live and Dead $^{\circledR}$ reactive (Life Sciences) following the manufacturer instructions. The analysis was done over a population gated considering planktonic sample, which contains single cells, avoiding biofilm aggregates. Untreated biofilm and planktonic cells were used as controls. ROS survival was assayed by comparing the increase in mortality between treated bacteria with its own population without treatment.

\section{Human cell toxicity assay}

MDA-MB-231 breast adenocarcinoma and HeLa cervical cancer cell lines were obtained from the American Type Culture Collection (ATCC) and were grown in RPMI 1640 and DEMEM glucose $(4.5 \mathrm{~g} / \mathrm{L})$ medium cultures, respectively, supplemented with glutamine $(2 \mathrm{mM})$, penicillin $(50 \mathrm{IU} / \mathrm{mL})$, streptomycin $(50 \mathrm{mg} / \mathrm{L})$, amphotericin $(1.25 \mathrm{mg} / \mathrm{L})$, and $10 \% \mathrm{FBS}$, at $37^{\circ} \mathrm{C}$ with $5 \% \mathrm{CO}_{2}$ in air. Cells were seeded at $2000 \mathrm{MDA}$ and 1500 HeLa cells/ well in a 96-well plate and incubated for $72 \mathrm{~h}$ at $37^{\circ} \mathrm{C}$ and $5 \% \mathrm{CO}_{2}$ to achieve confluence and a cell density of $1 \times 10^{4}$ cells/well. HeLa and MDA cell medium culture were replaced with 'assay culture' (supplemented with glutamine and FBS, without antibiotics), the cells were incubated for $2 \mathrm{~h}$, and then the culture medium was replaced again with assay culture.

$B$. cereus ATCC14579 was streaked onto an LB agar plate and incubated for $24 \mathrm{~h}$ at $28^{\circ} \mathrm{C}$. The $B$. cereus biomass was suspended in LB and seeded into a 24-well plate with $1 \mathrm{ml}$ of TyJ and incubated for $48 \mathrm{~h}$. Biofilm and floating cells were separated following the method described above. Both cell fractions of $B$. cereus were washed twice with sterile PBS, and the OD600 was adjusted to $1\left(\sim 10^{7} \mathrm{cfu} / \mathrm{ml}\right) .2-10 \mu$ of the suspension was added to each well in a 96-well cell culture plates containing $200 \mu \mathrm{l}$ of human cell culture media. Plates were centrifuged $5 \mathrm{~min}$ at $2000 \times g$ to force the bacteria to contact with human cells adhered at the bottom. Propidium iodide (PI; $3 \mu \mathrm{M}$ final concentration) and DAPI $(2.5 \mu \mathrm{M}$ final concentration) were added to wells to check the viability state of the eukaryotic cells. The time-lapse assay was performed using an Operetta high content screening microscope (Perkin Elmer) using a 10x dry objective, maintaining plates at $37^{\circ} \mathrm{C}$ and $5 \% \mathrm{CO}_{2}$ throughout the assay. Fluorescence images for DAPI and PI were taken from each well every 15 min for $9+\mathrm{h}$. Cell death ratios calculations were obtained from 6 fields/ well and 3-well replicas for each bacteria/cell combination. The percentage of dead cells in each well was counted automatically using Harmony 
software (Perkin Elmer). Mammalian nuclei were segmented based on their larger size $\left(>60 \mu \mathrm{m}^{2}\right)$ and higher DAPI staining intensities. Stuck together nuclei and the large bacterial aggregates were then filtered out by only selecting nuclei with a high degree of roundness (within $80 \%$ of a perfect circle). This segmented population was then analyzed for nuclear PI staining intensity, with only those nuclei higher than the PI threshold value (>200) recorded as dead cells with the remainder scored as live cells.

\section{Crystal violet assay}

B. cereus was grown in $1 \mathrm{ml}$ of TyJ medium in $4.5 \mathrm{~mm}$ diameter plates. Biofilms were stained by removing the spent medium and filling the well with $2 \mathrm{ml}$ of $1 \%$ crystal violet for $5 \mathrm{~min}$, followed by three washing steps with deionized water. The crystal violet was then resuspended with $50 \%$ acetic acid. Finally, the absorbance was measured at $595 \mathrm{~nm} \cdot{ }^{16}$ Statistical significance was assessed by repeated measures ANOVA with post-hoc paired Student's $t$-test. Results with $p<0.05$ were considered statistically significant.

\section{Reporting summary}

Further information on research design is available in the Nature Research Reporting Summary linked to this article.

\section{DATA AVAILABILITY}

Transcriptomic data have been submitted to NCBI GEO: https://www.ncbi.nlm.nih. gov/geo/query/acc.cgi?acc=GSE115528. The mass spectrometry proteomics data have been deposited to the ProteomeXchange Consortium via the PRIDE [1] partner repository with the dataset identifier PXD010211.

Received: 19 July 2019; Accepted: 16 December 2019;

Published online: 15 January 2020

\section{REFERENCES}

1. Hu, H.-J. et al. Endophytic Bacillus cereus effectively controls Meloidogyne incognita on tomato plants through rapid Rhizosphere occupation and repellent action. Plant Dis. 101, 448-455 (2017).

2. Kusama, Y., Honma, I., Masuda, M., Goto, H. \& Onodera, S. Bacillus cereus outbreak in normal neonates at our. Hospital. Jpn. J. Infect. Prev. Control 30, 385-390 (2015).

3. Fiedoruk, K. et al. Ribosomal background of the Bacillus cereus group thermotypes. Sci. Rep. 7, 46430 (2017).

4. Stetten, F., Mayr, R. \& Scherer, S. Climatic influence on mesophilic Bacillus cereus and psychrotolerant Bacillus weihenstephanensis populations in tropical, temperate and alpine soil. Environ. Microbiol. 1, 503-515 (1999).

5. Helgason, E. et al. Bacillus anthracis, Bacillus cereus, and Bacillus thuringiensis -one species on the basis of genetic evidence. Appl. Environ. Microbiol. 66, 2627-2630 (2000).

6. Anwar, M. S. et al. Multitrait plant growth promoting (PGP) rhizobacterial isolates from Brassica juncea rhizosphere. Commun. Integr. Biol. 7, e27683 (2014).

7. Zhu, K. et al. Probiotic Bacillus cereus Strains, a Potential Risk for Public Health in China. Front. Microbiol. 7, 718 (2016).

8. Wan, H. et al. Corrosion effect of Bacillus cereus on X80 pipeline steel in a Beijing soil environment. Bioelectrochemistry 121, 18-26 (2018).

9. Schultz, M. P., Bendick, J. A., Holm, E. R. \& Hertel, W. M. Economic impact of biofouling on a naval surface ship. Biofouling 27, 87-98 (2011).

10. Rajasekar, A. et al. Biodegradation and corrosion behavior of manganese oxidizer Bacillus cereus ACE4 in diesel transporting pipeline. Corros. Sci. 49, 2694-2710 (2007).

11. Gurler, N., Oksuz, L., Muftuoglu, M., Sargin, F. \& Besisik, S. Bacillus cereus catheter related bloodstream infection in a patient with acute lymphoblastic leukemia. Mediterr. J. Hematol. Infect. Dis. 4, e2012004 (2012).

12. Jamal, M. et al. Bacterial biofilm and associated infections. J. Chin. Med. Assoc. 81, 7-11 (2018).

13. Vlamakis, H., Chai, Y., Beauregard, P., Losick, R. \& Kolter, R. Sticking together: building a biofilm the Bacillus subtilis way. Nat. Rev. Microbiol. 11, 157-168 (2013).

14. Majed, R., Faille, C., Kallassy, M. \& Gohar, M. Bacillus cereus biofilms-same, only different. Front. Microbiol. 7, 1054 (2016).

15. Branda, S. S., Gonzalez-Pastor, J. E., Ben-Yehuda, S., Losick, R. \& Kolter, R. Fruiting body formation by Bacillus subtilis. Proc. Natl Acad. Sci. USA 98, 11621-11626 (2001).
16. Caro-Astorga, J., Pérez-García, A., de Vicente, A. \& Romero, D. A genomic region involved in the formation of adhesin fibers in Bacillus cereus biofilms. Front. Microbiol. 5, 745 (2015).

17. Arnaouteli, S. et al. Bifunctionality of a biofilm matrix protein controlled by redox state. Proc. Natl Acad. Sci. USA 114, E6184-E6191 (2017).

18. Fagerlund, A. et al. SinR controls enterotoxin expression in Bacillus thuringiensis biofilms. PLOS ONE 9, e87532 (2014).

19. Gao, T., Foulston, L., Chai, Y., Wang, Q. \& Losick, R. Alternative modes of biofilm formation by plant-associated Bacillus cereus. MicrobiologyOpen 4, 452-464 (2015).

20. Kristoffersen, S. M. et al. Global mRNA decay analysis at single nucleotide resolution reveals segmental and positional degradation patterns in a Gram-positive bacterium. Genome Biol. 13, R30 (2012).

21. Chaloupka, J., Strnadová, M. \& Moravcová, J. Protein turnover in growing cultures of Bacillus megaterium. Acta Biol. Med. Ger. 40, 1227-1234 (1981).

22. $\mathrm{Xu}$, S. et al. The spo0A-sinl-sinR regulatory circuit plays an essential role in biofilm formation, nematicidal activities, and plant protection in Bacillus cereus AR156. Mol. Plant-Microbe Interact. MPMI 30, 603-619 (2017).

23. Hsueh, Y.-H., Somers, E. B., Lereclus, D. \& Wong, A. C. L. Biofilm formation by Bacillus cereus is influenced by $\mathrm{PlcR}$, a pleiotropic regulator. Appl. Environ. Microbiol. 72, 5089-5092 (2006).

24. Bridier, A. et al. The spatial architecture of Bacillus subtilis biofilms deciphered using a surface-associated model and in situ imaging. PLOS ONE 6, e16177 (2011).

25. Lemon, K. P., Earl, A. M., Vlamakis, H. C., Aguilar, C. \& Kolter, R. Biofilm development with an emphasis on Bacillus subtilis. Curr. Top. Microbiol. Immunol. 322, 1-16 (2008).

26. Limoli, D. H., Jones, C. J. \& Wozniak, D. J. Bacterial extracellular polysaccharides in biofilm formation and function. Microbiol. Spectr. 3, MB-0011-2014 (2015).

27. Newman, J. A., Rodrigues, C. \& Lewis, R. J. Molecular basis of the activity of SinR protein, the master regulator of biofilm formation in Bacillus subtilis. J. Biol. Chem. 288, 10766-10778 (2013).

28. Okshevsky, M. et al. A transposon mutant library of Bacillus cereus ATCC 10987 reveals novel genes required for biofilm formation and implicates motility as an important factor for pellicle-biofilm formation. MicrobiologyOpen 7, e00552 (2018).

29. Vilain, S., Pretorius, J. M., Theron, J. \& Brözel, V. S. DNA as an adhesin: Bacillus cereus requires extracellular DNA to form biofilms. Appl. Environ. Microbiol. 75, 2861-2868 (2009)

30. Yan, F. et al. Genome-wide investigation of biofilm formation in Bacillus cereus. Appl. Environ. Microbiol. 83, e00561-17 (2017).

31. Visick, J. E. \& Clarke, S. Repair, refold, recycle: how bacteria can deal with spontaneous and environmental damage to proteins. Mol. Microbiol. 16, 835-845 (1995).

32. Liu, J. et al. Metabolic co-dependence gives rise to collective oscillations within biofilms. Nature 523, 550-554 (2015).

33. Hassanov, T., Karunker, I., Steinberg, N., Erez, A. \& Kolodkin-Gal, I. Novel antibiofilm chemotherapies target nitrogen from glutamate and glutamine. Sci. Rep. 8, 7097-7097 (2018).

34. Paul, B. J. et al. DksA: a critical component of the transcription initiation machinery that potentiates the regulation of rRNA promoters by ppGpp and the initiating NTP. Cell 118, 311-322 (2004).

35. Bucher, T., Oppenheimer-Shaanan, Y., Savidor, A., Bloom-Ackermann, Z. \& Kolodkin-Gal, I. Disturbance of the bacterial cell wall specifically interferes with biofilm formation. Environ. Microbiol. Rep. 7, 990-1004 (2015).

36. Zhu, X. et al. Tunicamycin mediated inhibition of wall teichoic acid affects Staphylococcus aureus and Listeria monocytogenes cell morphology, biofilm formation and virulence. Front. Microbiol. 9, 1352 (2018).

37. Abi Khattar, Z. et al. The dlt operon of Bacillus cereus is required for resistance to cationic antimicrobial peptides and for virulence in insects. J. Bacteriol. 191, 7063-7073 (2009).

38. Walter, J. et al. D-alanyl ester depletion of teichoic acids in Lactobacillus reuteri 100-23 results in impaired colonization of the mouse gastrointestinal tract. Environ. Microbiol 9, 1750-1760 (2007).

39. Gross, M., Cramton, S. E., Gotz, F. \& Peschel, A. Key role of teichoic acid net charge in Staphylococcus aureus colonization of artificial surfaces. Infect. Immun. 69, 3423-3426 (2001).

40. Kristian, S. A. et al. D-alanylation of teichoic acids promotes a Streptococcus antimicrobial peptide resistance, neutrophil survival, and epithelial cell invasion. J. Bacteriol. 187, 6719-6725 (2005).

41. Peschel, A. et al. Inactivation of the dlt operon in Staphylococcus aureus confers sensitivity to defensins, protegrins, and other antimicrobial peptides. J. Biol. Chem. 274, 8405-8410 (1999).

42. Couñago, R. M., Davlieva, M., Strych, U., Hill, R. E. \& Krause, K. L. Biochemical and structural characterization of alanine racemase from Bacillus anthracis (Ames). BMC Struct. Biol. 9, 53 (2009). 
43. Bosák, J., Micenková, L., Doležalová, M. \& Šmajs, D. Colicins U and Y inhibit growth of Escherichia coli strains via recognition of conserved OmpA extracellular loop 1. Int. J. Med. Microbiol. https://doi.org/10.1016/j.ijmm.2016.07.002 (2016).

44. Van Acker, H. \& Coenye, T. The role of reactive oxygen species in antibioticmediated killing of bacteria. Trends Microbiol. 25, 456-466 (2017).

45. Vatansever, F. et al. Antimicrobial strategies centered around reactive oxygen species-bactericidal antibiotics, photodynamic therapy, and beyond. FEMS Microbiol. Rev. 37, 955-989 (2013).

46. Hirst, J., King, M. S. \& Pryde, K. R. The production of reactive oxygen species by complex I. Biochem. Soc. Trans. 36, 976-980 (2008).

47. Ahn, S., Jung, J., Jang, I.-A., Madsen, E. L. \& Park, W. Role of glyoxylate shunt in oxidative stress response. J. Biol. Chem. 291, 11928-11938 (2016).

48. Hamzeh-Cognasse, $\mathrm{H}$. et al. Platelets and infections-complex interactions with bacteria. Front. Immunol. 6, 82 (2015).

49. Dalhammar, G. \& Steiner, H. Characterization of inhibitor A, a protease from Bacillus thuringiensis which degrades attacins and cecropins, two classes of antibacterial proteins in insects. Eur. J. Biochem. 139, 247-252 (1984).

50. Terwilliger, A. et al. Bacillus anthracis overcomes an amino acid auxotrophy by cleaving host serum proteins. J. Bacteriol. 197, 2400-2411 (2015).

51. Ramarao, N. \& Lereclus, D. The InhA1 metalloprotease allows spores of the $B$. cereus group to escape macrophages: InhA1 allows $B$. thuringiensis escape from macrophages. Cell. Microbiol 7, 1357-1364 (2005).

52. Ramarao, N. \& Sanchis, V. The pore-forming Haemolysins of Bacillus cereus: a review. Toxins 5, 1119-1139 (2013).

53. Dierick, K. et al. Fatal family outbreak of Bacillus cereus-associated food poisoning. J. Clin. Microbiol. 43, 4277-4279 (2005).

54. de Jong, A., van der Meulen, S., Kuipers, O. P. \& Kok, J. T-REx: Transcriptome analysis webserver for RNA-seq Expression data. BMC Genomics 16, 663 (2015).

55. Heel, V. et al. BAGEL3: automated identification of genes encoding bacteriocins and (non-)bactericidal posttranslationally modified peptides. Nucleic Acids Res. 41, W448-W453 (2013)

56. Medema, M. H. et al. antiSMASH: rapid identification, annotation and analysis of secondary metabolite biosynthesis gene clusters in bacterial and fungal genome sequences. Nucleic Acids Res. 39, W339-W346 (2011)

57. Szklarczyk, D. et al. The STRING database in 2017: quality-controlled proteinprotein association networks, made broadly accessible. Nucleic Acids Res. 45, D362-D368 (2017).

58. Shannon, P. et al. Cytoscape: a software environment for integrated models of biomolecular interaction networks. Genome Res. 13, 2498-2504 (2003).

59. Newman, M. E. J. \& Girvan, M. Finding and evaluating community structure in networks. Phys. Rev. E Stat. Nonlin. Soft Matter Phys. 69, 026113 (2004).

60. Huang, D. W. et al. The DAVID Gene Functional Classification Tool: a novel biological module-centric algorithm to functionally analyze large gene lists. Genome Biol. 8, R183 (2007)

61. Ashburner, M. et al. Gene Ontology: tool for the unification of biology. Nat. Genet. 25, 25-29 (2000)

62. Kanehisa, M. The KEGG database. Novartis Found. Symp. 247, 91-101 (2002)

63. Belliveau, B. H. \& Trevors, J. T. Transformation of Bacillus cereus vegetative cells by electroporation. Appl. Environ. Microbiol. 55, 1649-1652 (1989).

\section{ACKNOWLEDGEMENTS}

We would like to thank Anne de Jong (University of Groningen) for technical support in the use of T-Rex platform, and Ana María Álvarez (University of Málaga) for helping in biofilm experiments. We also thank members of the electron microscopy, cell biology and cell cultures, confocal microscopy (Dr. John Pearson, Bionand) and mass spectrometry services of SCAI (University of Málaga) and the Mass Spectrometry service of CNB (Centro Nacional de Biotecnología - CSIC, Spain) for technical support and guidance, and to Miguel Ángel Medina Torres for providing us with human cell lines. Joaquín Caro-Astorga is the recipient of a FPI contract [BES-2013-064134] from Ministerio de Economía y Competitividad. James Perkins is funded by Sara Borrell program from Carlos III (CD14/00242). Juan Antonio Ranea is funded by grants from Spanish Ministry of Economy and Competitiveness [SAF2016-78041-C2-1-R] and Andalusian Government with European Regional Development Fund [CTS-486]. The CIBERER is an initiative from the Instituto de Salud Carlos III. This work was supported by grants [AGL2012-31968 and AGL2016-78662-R] from Ministerio de Economía y Competitividad, Spanish Government and European Research Council Starting Grant under Grant [BacBio 637971].

\section{AUTHOR CONTRIBUTIONS}

Conception or design of the work; D.R., J.C.A. Acquisition, analysis, or interpretation of data for the work: D.R., J.C.A., O.K., E.F., J.A.R., J.R.P., A.A.M. Drafting the work: D.R., J.C. A. Revising it critically for important intellectual content: D.R., J.C.A., O.K., E.F., AdV. Final approval of the version to be published: D.R., J.C.A., O.K., E.F., J.R.P., AdV, J.A.R.

\section{COMPETING INTERESTS}

The authors declare no competing interests.

\section{ADDITIONAL INFORMATION}

Supplementary information is available for this paper at https://doi.org/10.1038/ s41522-019-0112-7.

Correspondence and requests for materials should be addressed to D.R.

Reprints and permission information is available at http://www.nature.com/ reprints

Publisher's note Springer Nature remains neutral with regard to jurisdictional claims in published maps and institutional affiliations.

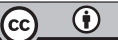

Open Access This article is licensed under a Creative Commons Attribution 4.0 International License, which permits use, sharing, adaptation, distribution and reproduction in any medium or format, as long as you give appropriate credit to the original author(s) and the source, provide a link to the Creative Commons license, and indicate if changes were made. The images or other third party material in this article are included in the article's Creative Commons license, unless indicated otherwise in a credit line to the material. If material is not included in the article's Creative Commons license and your intended use is not permitted by statutory regulation or exceeds the permitted use, you will need to obtain permission directly from the copyright holder. To view a copy of this license, visit http://creativecommons. org/licenses/by/4.0/.

(c) The Author(s) 2020 